CUADERNOS DE ESTUDIOS GALLEGOS, LXII Núm. 128 (enero-diciembre 2015), págs. 207-247

ISSN: $0210-847 \mathrm{X}$

DOI: $10.3989 /$ ceg.2015.128.07

\title{
LA LITERATURA DE VIAJES Y EL TRANSPORTE EN GALICIA \\ DESDE EL ÚLTIMO TERCIO DEL SIGLO XVIII HASTA MEDIADOS DEL XIX*
}

\author{
Elvira Lindoso-Tato \\ Margarita Vilar-RodrígueZ \\ Universidade da Coruña
}

* Este trabajo se ha realizado con la financiación del proyecto Historia del Turismo en Galicia. Origenes y Desarrollo en el siglo XX, Ref. HAR2014-52023-C2-2-P (Secretaría de Investigación, España). 


\section{LA LITERATURA DE VIAJES Y EL TRANSPORTE TERRESTRE EN GALICIA DESDE EL ÚLTIMO TERCIO DEL SIGLO XVIII HASTA MEDIADOS DEL XIX}

RESUMEN

España, en general, y Galicia, en particular, permanecieron alejadas de las rutas del Grand Tour, exponente principal del turismo moderno iniciado en Gran Bretaña. El desconocimiento del territorio y el deficiente estado de los transportes terrestres contribuyeron a este alejamiento, entre otros factores. Así, el trabajo se centra en el análisis de ambos obstáculos al primer desarrollo del turismo en Galicia entre finales del siglo XVIII y mediados del siglo XIX, antes de la construcción del ferrocarril. Por un lado, se analiza la imagen que ofrecieron algunos viajeros extranjeros en sus crónicas de viaje por tierras galaicas y, por otro lado, se estudia el estado del transporte terrestre de la época. Se observa que los testimonios forasteros sobre la región gallega resultaron escasos en comparación con otros puntos peninsulares aunque aliviaron en cierto grado el desconocimiento que pesaba sobre la comunidad, marcando una serie de puntos de futuro interés turístico. Por último, se realizaron una serie de avances en el transporte terrestre que mejoraron sólo de manera parcial la accesibilidad turística en el último tercio del siglo XVIII.

Palabras ClaVE: siglos XVIII y XIX, Galicia, turismo, transporte, guía turística.

\section{A LITERATURA DE VIAXES E O TRANSPORTE TERRESTRE EN GALICIA DENDE O ÚLTIMO TERZO DO SÉCULO XVIII ATA MEDIADOS DO XIX}

RESUMO

España, en xeral, e Galicia, en particular, permaneceron afastadas das rutas do Grand Tour, expoñente principal do turismo moderno iniciado en Gran Bretaña. O descoñecemento do territorio e o deficiente estado dos transportes terrestres contribuíron a este afastamento, entre outros factores. Así, o traballo céntrase na análise de ambos os dous obstáculos ao primeiro desenvolvemento do turismo en Galicia entre finais do século XVIII e mediados do século XIX, antes da construción do ferrocarril. Por un lado, analízase a imaxe que ofreceron algúns viaxeiros estranxeiros nas súas crónicas de viaxe por terras galaicas e, por outro lado, estúdase o estado do transporte terrestre da época. Obsérvase que os testemuños forasteiros sobre a rexión galega resultaron escasos en comparación con outros puntos peninsulares aínda que aliviaron en certo grao o descoñecemento que pesaba sobre a comunidade, marcando unha serie de puntos de futuro interese turístico. Por último, realizáronse unha serie de avances no transporte terrestre que melloraron só de xeito parcial a accesibilidade turística no último terzo do século XVIII. PALABRas ClaVE: séculos XVIII e XIX, Galicia, turismo, transporte, guía turística.

\section{TRAVEL LITERATURE AND LAND TRANSPORTATION IN GALICIA FROM THE LATE THIRD OF THE $18^{\mathrm{TH}}$ CENTURY UNTIL THE MIDDLE OF THE $19^{\mathrm{TH}}$ CENTURY ABSTRACT}

Spain, in general, and Galicia, in particular, stayed away from the Grand Tour, major exponent of the modern tourism born in Great Britain. The ignorance of the land and the poor ground transportation contributed to this distance, among other things. In this way, the paper focuses in the analysis of both obstacles in the first tourism development in Galicia, between the late eighteenth century and the mid-nineteenth century, before the railway construction. On the one hand, it analyses the image that some foreign travelers offered about their travels in Galicia, and, on the other hand, it studies the state of the ground transportation during the period. The foreign testimonies about the Galician region were short compared with other parts of the peninsula. Although they relieved in certain degree the ignorance about Galicia with the marking of some points of future tourist interest. At last, several and partial improvements in the ground transportation were made in the last third of the eighteenth century.

KEY WORDS: $18^{\text {th }}$ and $19^{\text {th }}$ centuries, Galicia, tourism, transport, travel guide. 
Recibido/Received: 25/05/2015

Aceptado/Accepted: 27/07/2015

\section{INTRODUCCIÓN}

$\mathrm{V}$

iajar por placer, una de las definiciones clásicas del turismo, constituyó una práctica que se instaló progresivamente en la Europa del siglo XIX en el marco de la industrialización, aunque sus antecedentes pueden rastrearse hasta la segunda mitad del siglo XVIII ${ }^{1}$. La mayor parte de los estudiosos coinciden en señalar como patria del turismo moderno a Gran Bretaña, país pionero de la Revolución Industrial e impulsor de nuevas modas y pautas de consumo ${ }^{2}$. Así, el nacimiento del turismo como fenómeno social y económico se vincula con el británico Grand Tour, un viaje iniciático hacia la madurez de los caballeros ingleses de alta cuna, que surgió en el siglo XVI y que se mantuvo con algunas modificaciones hasta las guerras napoleónicas ${ }^{3}$. La duración del viaje resultaba variable, pero no era extraño que se midiese en años, durante los cuales los jóvenes de buena posición podían visitar, si su presupuesto se lo permitía, Bélgica, Francia, Suiza, Alemania y, en especial, Italia, donde acudían

1 El surgimiento de las grandes ciudades termales en Europa y el descubrimiento de los baños marinos se encuentran entre esos antecedentes, véase Carlos LARRINAGa y Rafael VALLEJo, "El turismo en el desarrollo español contemporáneo", Transportes, Servicios y Telecomunicaciones, 24, (2013), págs. 12-27. Para ampliar los aspectos relacionados con el turismo de salud, véanse Luis ALONSO ÁlvareZ, Margarita Vilar Rodríguez y Elvira Lindoso Tato, El agua bienhechora. El turismo termal en España, 1700-1936, Alhama de Granada, Observatorio nacional del Termalismo, 2012 y Luis Alonso Alvarez, Elvira Lindoso Tato y Margarita Vilar Rodríguez, O lecer das augas. Historia dos balnearios de Galicia, 1700-1936, Vigo, Galaxia, 2011.

2 Ana Moreno Garrido, Historia del turismo en España en el siglo XX, Madrid, Síntesis, 2007, págs. 15-24 y Ana Moreno Garrido, "Historia del turismo: una investigación necesaria", en $V$ Jornadas de Investigación en Turismo. Turismo y Sostenibilidad, Sevilla, 17-18 de mayo, 2012, págs. 105126. En realidad, los viajes por placer se pueden rastrear desde la Antigüedad, pero no se trataba de una práctica generalizada, por lo que no todos los viajeros se podrían calificar como turistas, véanse Marc Boyer, "El turismo en Europa, de la Edad Moderna al siglo XX", Historia Contemporánea (II) 25, (2002), págs. 13-31 y José M. FARALDO JARILlo y Carolina Rodríguez-López, Introducción a la historia del turismo, Madrid, Alianza, 2013, págs. 17 y ss.

3 Según J. M. Faraldo y C. Rodríguez-López, Introducción ..., págs. 17 y ss., el primer empleo del término inglés "tourism" data del año 1800 , mientras que la palabra "turiste" se encuentra por primera vez en un texto francés de 1816. En España, la voz "turismo" no figurará en el diccionario de la Real Academia de la Lengua Española hasta el año 1925, más de un siglo después. 
ávidos de adquirir formación y cultura clásicas así como de realizar todo tipo de actividades lúdicas. En contadas ocasiones recorrían otros países como Grecia, Turquía o España. Esta última quedaba lejos de las aspiraciones viajeras de las nuevas generaciones. El país resultaba un gran desconocido para la mayoría de los europeos y la información disponible solía estar plagada de tópicos difíciles de erradicar.

El fenómeno del Grand Tour se exportó al resto de Europa y acabó acogiendo amplios grupos de la sociedad burguesa durante el siglo XIX ${ }^{4}$. Sin embargo, antes de la II Guerra Mundial, el turismo constituyó una actividad discreta ligada a las clases sociales más pudientes y ociosas. Según Boyer (2002), el vocablo turista surgió en la época romántica y se aplicó al "viajero inglés rico y curioso que con su guía visita todo lo que debe ser visto"s. De hecho, la actividad turística conservó su naturaleza elitista hasta la segunda mitad del siglo XX cuando se generalizó con la incorporación de las clases medias y la aparición del denominado turismo de masas $^{6}$.

España, en general, y Galicia, en particular, apenas se integraron en las rutas del Grand Tour. Sin embargo, desde el último tercio del siglo XVIII se despierta un nuevo interés por viajar a España que se transformará en moda durante el siglo XIX 7 . De hecho, los Borbones, con el rey Carlos III como principal exponente, propiciaron una política de apertura al exterior de tal forma que en Madrid, Barcelona o Sevilla se dejaron sentir las modas y usos importados de Francia e Italia y también de Inglaterra y Alemania. Las nuevas modas en el viajar se vieron alimentadas por determinada literatura de viajes -libros, colecciones de cartas y ensayos esenciales para conocer lo que debía ser visto- que empezaron a cambiar la pobre opinión que muchos mantenían de España y sus gentes y colocaron en el mapa pre-turístico a la península Ibérica, transformándola en un destino atrayente para algunos visitantes elitistas y/o aventureros. Incluso la guerra de la Independencia contribuyó a aliviar el desconocimiento sobre el territorio

\footnotetext{
4 Para ampliar este tema, véanse John Walter Stoye, English Traveller Abroad, 1604-1667: Their Influence in English Society and Politics, Londres, J. Cape, 1952, M. BOYER, "El turismo...", págs. 13-31 y Jeremy Black, The British Abroad The Grand Tour in the Eighteenth Century, Londres, Allan Sutton, 2003.

5 M. BOYER, "El turismo...", págs. 13-31 incorpora otras definiciones como la de Littré, que define al turista como aquel individuo que viaja por ociosidad y curiosidad.

6 Bertram M. Gordon, "Turismo de Masas: un concepto problemático en la historia del siglo XX", Historia Contemporánea, II, 25, (2002), págs. 125-156 y Sasha D. PACK, "Turismo en la Europa de la postguerra: de la diplomacia esterliniana al consumismo de masas", Transportes, Servicios y Telecomunicaciones, 24, (2013), págs. 138-166.

7 Jesusa VEGA, "Viajar a España en la primera mitad del siglo XIX: Una aventura lejos de la civilización”, RDTP, LIX, 2 (2004), págs. 93-125. Pese al despertar de ese interés, el turismo constituía aún un fenómeno socioeconómico limitado en la España del siglo XIX, véase Carlos LaRRINAGA, "El turismo en la España del siglo XIX”, Historia Contemporánea, II, 25 (2002), págs. 157-179.
} 
español. Durante el conflicto, España se convirtió en territorio de paso tanto para los ejércitos napoleónicos como para nuestros aliados europeos. Al regresar a sus hogares, algunos transmitieron sus impresiones sobre el país llegando a editar las memorias de aquellas jornadas. Así, las guerras napoleónicas, pese a la devastación que causaron y las trabas que imponían a los desplazamientos, sirvieron para que militares y civiles que llegaban tanto con los ejércitos invasores como con los aliados mirasen al viejo país con nuevos ojos y difundiesen posteriormente de manera escrita o verbal algunas de sus virtudes iniciando un cambio de visión del mismo.

De esta forma, uno de los principales obstáculos inmateriales para el desarrollo del turismo - el desconocimiento o la ignorancia del país que desembocaban en falta de interés y pobre opinión sobre el mismo-comenzaba a cambiar de manera incipiente $^{8}$. Sin embargo, se mantenían otras barreras físicas relacionadas con la orografía, el mal estado de los caminos y la precaria red de transportes ${ }^{9}$. Por ejemplo, Friederich-Stegmann (2014) en su trabajo sobre la imagen de España en los diarios de diversos viajeros alemanes señala como al acabar la guerra de los Siete años se intensificaron los viajes por toda Europa y, en el caso de España, relacionó claramente esos viajes con la mejora de los caminos ${ }^{10}$. La limitación física que suponían los deficientes transportes terrestres durante gran parte del siglo XVIII, e incluso del siglo XIX, condicionaban la inclusión del territorio en las incipientes corrientes turísticas internacionales y sumían a veces en el olvido a las regiones en peores condiciones ${ }^{11}$. En este caso se encontraba Galicia, una de las regiones

8 Carlos ARCos y CUADRA, De las grandes ventajas económicas que produciría el desarrollo del turismo en España, Barcelona, Banca Mas Sardá, 1909 [1974], en un trabajo citado por Carmelo Pellejero, "Antecedentes históricos del turismo en España: de la Comisión Nacional al Ministerio de Información y Turismo (1900-1950)" en Carmelo Pellejero Martínez (dir.), Historia de la economía del turismo en España, Madrid, Civitas, 1999, págs. 21-76, todavía apuntaba al desconocimiento que de España existía en el extranjero como uno de los motivos que limitaban los visitantes que recibía el país. Entre estos, también se encontraban el mal estado del transporte terrestre y la deficiente oferta hotelera a principios del siglo XX.

9 Las infraestructuras y los medios de transporte han sido considerados por la historiografía como elementos claves en el proceso de desarrollo de los países, véanse las obras clásicas de Nicolás SÁnchez-Albornoz, España hace un siglo: una economía dual, Alianza, Madrid, 1977 y Antonio Gómez MendozA, Ferrocarriles y cambio económico en España (1855-1913). Un enfoque de nueva historia económica, Alianza, Madrid, 1982. Una síntesis reciente sobre la historia de las infraestructuras españolas puede verse en Alfonso HerRanz LoncÁN, Infraestructure and Economic Growth in Spain, 1845-1935, London School of Economics and Political Science, Tesis doctoral, 2002.

${ }_{10}$ Hiltrud Friederich-Stegmann, La imagen de España en los libros de los viajeros alemanes del siglo XVIII, Alicante, Universidad de Alicante, 2014, pág. 84.

${ }^{11}$ Carlos Larrinaga, "Ferrocarriles y termalismo: la configuración del espacio balneario en el País Vasco" en Novo, P. A., Parejo, A. (eds.), Ferrocarriles y sociedad urbana en el País Vasco, Universidad del País Vasco, 2015, págs. 208-242 pone de manifiesto el papel que jugaron los medios de transporte en la construcción de los espacios turísticos al relacionar el desarrollo del turismo termal vasco con la extensión de las redes ferroviarias. 
más pobladas a finales del Antiguo Régimen, pero que contaba con algunos de los peores accesos terrestres. En paralelo, la literatura de viajes marginó en muchas ocasiones a la comunidad gallega, tal y como veremos a lo largo del texto. No siempre los curiosos y ociosos viajeros se animaron a llegar al extremo noroeste, mientras que otros puntos peninsulares recibían mayor atención ${ }^{12}$. Asimismo, la situación de los caminos resultó deplorable y sólo a lo largo del siglo XVIII dio señales de avances positivos. Por ejemplo, el diario de viaje del ilustrado Fray Martín Sarmiento señalaba en 1745 que el camino desde Sobrado hasta Santiago discurría por ocho leguas de buen camino, pero todo sierra ${ }^{13}$.

Tomando como referencia geográfica a Galicia, uno de los territorios más desconocidos en la España de la época, y como anclaje temporal el período que abarca desde la segunda mitad del Setecientos hasta bien entrado el siglo Ochocientos, analizaremos la imagen de la comunidad gallega en la más destacada literatura de viajes sobre la España de la época con el fin de valorar su inclusión en el incipiente mapa turístico nacional de finales del Antiguo Régimen. Seguidamente, una vez identificado qué se conocía de Galicia y qué se debía ver según estas primitivas guías de viaje, examinaremos las opciones de transporte disponibles para aquellos primeros visitantes que se desplazaban al extremo noroeste peninsular. Con este fin, las siguientes páginas se articularán en dos epígrafes que englobarán a su vez dos grandes temas de estudio. Por un lado, el primero se refiere a la visión e impresiones sobre el reino gallego transmitidas por algunos ilustres viajeros entre finales del siglo XVIII y mediados del siglo XIX, visiones que pudieron ayudar a cambiar la imagen pobre y desconocida de Galicia por la de un territorio digno de la curiosidad forastera y no carente de atractivos ${ }^{14}$. Por otro lado, el segundo apartado se centra en uno de los grandes obstáculos materiales al desarrollo turístico de la región -el estado del transporte terrestre antes de la llegada del ferrocarril- sin dejar de mencionar también por su importancia el transporte marítimo. Finalmente, el texto se cierra con unas conclusiones.

\footnotetext{
${ }^{12}$ Podemos encontrar referencias a diversos ilustres viajeros que visitaron España y Galicia en las obras de José García Mercadal, España vista por los extranjeros, Madrid, Biblioteca Nueva, 19171920 ?, 3 vols., y de Gustavo A. GARRIDO, Aventureiros e curiosos: relatos de viaxeiros estranxeiros por Galicia (séculos XV-XX), Vigo, Galaxia, 1994.

${ }^{13}$ Fr. Martín Sarmiento, Viaxe a Galicia (1745), Noia, Edición de J. L. Pensado, Departamento de Filología Románica, Universidad de Salamanca, ToxoSoutos, 1975.

${ }^{14}$ E. López Lambas, El Camino Real de Galicia. Aspectos jurídicos, Facultad de Derecho. Universidad Complutense, Madrid, Tesis doctoral inédita, 1995 ya introducía breve y marginalmente el tema de los viajeros y el Grand Tour en su tesis sobre el camino Real gallego y sus aspectos jurídicos.
} 


\section{Galicia y LA Literatura DE VIAJES}

Las guías y diarios de viajes constituyeron, y aún constituyen, un instrumento esencial para conocer qué debe verse cuando se visita un país o un territorio ${ }^{15}$. En el caso español, los diarios de viajes de los forasteros que se animaron a visitar España durante el siglo XVIII y la primera mitad del siglo XIX resultan muy útiles para conocer las dimensiones de su atractivo turístico. Tal y como mencionamos anteriormente, en sus inicios, España permaneció alejada de las principales rutas del Grand Tour. Algunas de las ideas sobre el país difundidas en el extranjero no animaban precisamente a realizar tal viaje por placer ${ }^{16}$. Sin embargo, a finales del Setecientos, comenzaron a editarse diversos libros y cartas que ofrecían otra imagen sobre España. El viaje por territorio español se concebía como una aventura ante su falta de modernidad y ello atrajo a algunas personalidades que llegaron a publicar sus experiencias, de tal forma que sus palabras actuaron de embajadoras fuera de las fronteras. El decenio de 1770 resultó bastante prolífico en testimonios de este tipo.

Por un lado, nos encontramos con viajeros de distintas nacionalidades que relataron por escrito sus experiencias españolas pero dejaron a Galicia fuera de sus textos. Así, Richard Twiss, hijo de un comerciante holandés, movido por la curiosidad y amor a la diversidad y atraído por su arte y literatura tan distintos al resto de Europa, visitó España y Portugal en el bienio 1772-73 y publicó sus vivencias ${ }^{17}$. Su obra contribuyó a la difusión de los atractivos turísticos de Salamanca, Madrid, Aranjuez, Segovia, Toledo, Granada y Valencia, entre otras poblaciones españolas. Pero Galicia quedó fuera de su recorrido. Esta conducta no resultaba extraña en otros ilustres trotamundos de la época como el británico Henry Swinburne (1779), Jean-François Bourgoing Peyron (1783), John Talbot Dillon (1781) -desplazado a España en 1778 y que incorporó a su trabajo algunas de las observaciones de William Bowles ${ }^{18}$, manteniendo al noroeste peninsular

\footnotetext{
${ }^{15}$ El prototipo de una guía de viaje apareció por primera vez en el siglo XVI, véase M. BoYER, "El turismo...", págs. 13-31.

${ }^{16}$ Por ejemplo, J. VeGA, "Viajar...", págs. 93-125 recoge algunos fragmentos de la pobre opinión que despertaba España en algunos viajeros alemanes y británicos a finales del siglo XVIII.

${ }^{17}$ Richard Twiss, Travels through Portugal and Spain, in 1772 y 1773. Printed by Richard Twiss with an Appendix, Sold by G. Robinson, T. Becket and J. Robson, Lond0n-Dublín, 2 vols, 1775, págs. i-iii.

${ }^{18} \mathrm{La}$ obra de Bowles fue editada en 1775 y reeditada en 1782. Este irlandés estudió en París y conoció en 1752 a Antonio de Ulloa, comendador de Ocaña en la Orden de Santiago y Teniente General de la Armada, que le propuso viajar a España donde la Administración le encargó reparar la mina de Almadén. Su trabajo se prolongó visitando otras minas. Además se encargó de establecer un gabinete de historia natural y un laboratorio químico. Sin embargo, sus textos no se pueden encuadrar exactamente en la literatura de viajes dado que se centra en el estudio de la riqueza minera y de las especies vegetales y animales. En este sentido, constituye uno de los pocos autores que mencionan
} 
ausente de las 496 páginas de su obra-, el noble Jean Marie-Jêrome Fleuriot (1796), el francés Theophile Gautier (1845) y el inglés Joseph Townsend (1791). Este último recorrió buena parte de la península ibérica pero no pasó de Pedrafita, principal puerto de entrada a Galicia desde la Meseta. La peligrosidad del viaje quedó de manifiesto al ofrecernos una vívida imagen de la enorme cantidad de perros con collares de púas que se encontraban en la citada localidad para protegerse de los ataques de los numerosos lobos. Una experiencia así resultaba desalentadora para cruzar el puerto. El alemán Christian August Fischer, uno de los mayores difusores del conocimiento sobre España a principios del Ochocientos, tampoco integró las villas gallegas en su obra ${ }^{19}$. Esta actitud de los viajeros extranjeros no desentonaba de la nacional. Ni el valenciano Antonio Ponz ni el jienense Isidoro de Bosarte dedicaron una sola página a Galicia. El primero publicó dieciocho volúmenes en los que se recogen en gran medida los monumentos arquitectónicos y pictóricos de España, además de incluir textos históricos o económicos. En el caso de Isidro Bosarte, el primer tomo de su obra, publicada a principios del siglo XIX y más reducida que la de Antonio Ponz, sólo abarcó las riquezas artísticas de Segovia, Valladolid y Burgos. Ponz y Bosarte aglutinaron en sus obras gran parte del patrimonio artístico nacional pero ninguno se animó a visitar el noroeste peninsular.

En consecuencia, la zona noroeste peninsular resultaba desconocida de manera más intensa que el resto de la nación. No siempre ocurrió así. Durante la Edad Media, el activo Camino de Santiago que culminaba en la capital del reino de Galicia se transformó en una de las principales vías de comunicación entre Europa y el norte peninsular cristiano. La ruta jacobea constituía una de las arterias principales por la que circulaban viajeros, comerciantes, noticias, etc., y colocó al reino galaico en el mapa. Las peregrinaciones compostelanas, junto a las de Roma y Jerusalén, componían la tríada del peregrinaje en la religión cristiana. Con el descubrimiento de América y la expansión del imperio español otras rutas adquirieron mayor relevancia y la red viaria terrestre nacional se polarizó hacia las carreteras que unían Castilla con Sevilla, ciudad y puerto privilegiado en el comercio indiano hasta el siglo XVIII, cuando otros puertos se abrieron al tráfico americano ${ }^{20}$. Mientras tanto, el camino de Santiago quedaba relegado al olvido hasta su recuperación a finales del siglo XIX con el redescubrimiento del Santo

\footnotetext{
a Galicia. Por ejemplo, menciona el oro que se podían obtener de algunos ríos gallegos, las minas de estaño de Ourense o lo bien que se daban las patatas en el suelo gallego, véase Guillermo BowLes, Introducción a la Historia Natural, y a la Geografía Física de España, $2^{\mathrm{a}}$ edición corregida, Madrid, Imprenta Real, 1782, págs. 33-36 y 248.

${ }^{19}$ La investigadora H. Friederich-Stegmann, La imagen..., ha recogido diversos testimonios de viajeros germanos en España.

${ }^{20}$ Ignacio GonZÁlez TASCón, Historia del Transporte en España, INECO-TIFSA, 2005, pág. 163.
} 
Sepulcro del apóstol Santiago ${ }^{21}$. En cualquier caso, siguiendo a Boyer (2002) el peregrino de estas épocas no debería encuadrarse en la categoría actual de turista, dado que no viajaba ni por ocio ni por curiosidad. Su motivación para el viaje sería fundamentalmente religiosa. Durante la mayor parte de la Edad Moderna, Galicia tampoco semejaba ser visitada por placer. A sus puertos y caminos llegaban militares, funcionarios públicos, monarcas, comerciantes, industriales y trabajadores de otras tierras pero pocos lo hacían por el deseo expreso de conocer el país y adquirir nuevas experiencias vitales. Las obligaciones económicas, laborales o políticas pesarían más en el ánimo de los visitantes que los intereses puramente turísticos. Nuestros primeros turistas, además de ser difícilmente cuantificables, tendrían un marcado carácter elitista, tal y como sucedía en el resto del territorio español y así refleja la bibliografía ${ }^{22}$.

Por otro lado, en la literatura de viajes sobresalen un pequeño conjunto de relatos de forasteros que se animaron a viajar también a Galicia y publicaron sus vivencias, de tal forma que contribuyeron a difundir una imagen del antiguo reino de Galicia que perduró en el tiempo. Estos diarios se ubican en distintos momentos temporales. Así, Jardine y Laborde se desplazaron a la península hacia finales del siglo XVIII y principios del XX, mientras que Borrow y Ford lo hicieron en la década de los treinta del siglo XIX. Respecto al primero -el militar británico Alexander Jardine-, éste publicó dos extensos volúmenes sobre sus viajes a Berbería, Francia, España y Portugal. El segundo tomo se dedicó casi íntegramente a los dos últimos. En torno al 75\% de ese volumen abarcó España desarrollando temas tan diversos como la idiosincrasia nacional, la economía o la forma de gobierno y contribuyó a asociar el nombre de España a la aventura y al romance:

I think, the very mention of Spain awakens in the mind, especially of young people, ideas of something romantic and uncommon. [...] Many objects in this country concur to fill the mind with noble and pleasing sentiments ${ }^{23}$.

\footnotetext{
${ }^{21}$ Elvira Lindoso y Margarita VILAR, "El milenario Camino de Santiago desde una perspectiva histórica: la apuesta turística de Galicia" en Carlos Barciela et al. (eds.), La evolución de la industria turística en España e Italia, Institut Balear d'Economia, Conselleria d'Economia i Hisenda, Govern de las Illes Balears, 2011.

${ }^{22}$ Textos como el de A. Moreno Garrido, Historia del turismo..., o el de J. M. Faraldo Jarillo y C. Rodríguez-López, Introducción..., ponen de manifiesto este turismo de las élites propio de las etapas preturísticas, antes de la II Guerra Mundial.

${ }^{23}$ Alexander JARDINE, Letters from Barbary, France, Spain, Portugal, by an English officer. In two volumes, London, Printed for T. Cadell in the Strand, 1788, págs. 2-3.
} 
Curiosamente, constituyó uno de los pocos forasteros en dejar constancia de su paso por Galicia a finales del XVIII. Primero visitó el País Vasco y luego, siguiendo la costa, se dirigió a Galicia:

This corner of the peninsula lies even more out of the common track than the rest of it, and is therefore still less known; but it is the province of the most importance to Spain, except perhaps Catalonia $^{24}$.

La imagen que ofrece de Galicia está plagada de clichés e influenciada evidentemente por la religión protestante que profesaba el autor. A pesar de su análisis poco riguroso, su opinión resulta útil para constatar diversos aspectos relacionados con el transporte o el atractivo que podía generar el territorio para los visitantes foráneos.

Los galaicos no resultaron muy bien parados en sus observaciones. Jardine (1788) los definía como docile, obedient, mean, and ragged creatures y los comparaba con los pobres judíos de Gibraltar ${ }^{25}$. También refrendó las diferencias de carácter entre el norte y el sur de España. Destacó en varias ocasiones la pobreza gallega, su laboriosidad y la necesidad de emigrar temporalmente para sobrevivir:

These Gallegos seem mostly poor and ragged, are rather a small or short race of people, and have a strong resemblance to the peasantry of some of the French provinces. [...] They are tolerably industrious, or rather laborious, but without much spirit or skill in their industry. [...] Galicia however, though poor, is of great importance to Spain, particularly in two chief articles of export, cattle and people. [...] Forty or fifty thousand of these Gallegos are computed to be thus employed. Some of them returned with a little money; and what does not go to the church, is hoarded, and often buried. [...] The poor ragged Gallegos are, however, rather industrious in their ignorant and coarse way. They are frugal to a degree of misery, and especially the women: who likewise perform the hardest labour in the fields, as frequently as the men, or more ${ }^{26}$.

\footnotetext{
${ }^{24}$ A. JARDINE, Letters..., págs. 106.

${ }^{25}$ A. JARDine, Letters..., pág. 251.

${ }^{26}$ A. JARDINE, Letters..., págs. 55-56.
} 
En paralelo, Jardine (1788) realizó también diversos apuntes económicos sobre la comunidad. Así, en Ribadeo hizo notar los restos de una otrora notable manufactura de lino. El sistema de propiedad sobre la tierra, sometida al sistema foral, las obras públicas - con influencia francesa-, la construcción de barcos y la formación de los marinos y las diferencias en precios y salarios entre distintas localidades (por ejemplo, el precio del trabajo en Ferrol casi doblaba al de Mondoñedo) también despertaron sus críticas.

Su naturaleza protestante y ser objeto de un robo mientras viajaba por Galicia, no predispuso favorablemente al forastero Jardine (1788) a la hora de emitir su opinión sobre el territorio. Pocos piropos le dedica a la región ${ }^{27}$. El clima saludable que le atribuye constituye uno de sus escasos apelativos positivos. Aunque visitó la capital del reino, Santiago, la identificó como capital de "superstición". No encontraba digno de admirar ni las calles -ruidosas y sucias- ni los edificios de Compostela cuyo diseño urbanístico resultaba más acorde, en sus palabras, con gustos bárbaros. Sólo consideraba dignos de apreciar San Martín Pinario y la música eclesiástica de la catedral ${ }^{28}$. Evidentemente, esta visión no resultaba demasiado atrayente para los potenciales turistas. A todo esto había que sumar un tema recurrente en la literatura de viajes en España, en general, y en Galicia, en particular: el mal estado de las infraestructuras viarias:

Neither roads, inns, nor tolerable workmen in any trade, to be found; but plenty of customhouses, and their officers, every where, to torment every passenger. And yet there is more smuggling in this country than any where else. Many churches, and many beggars; there generally go together. [...] The pilgrimage to St. Jago, though much diminished, still occasions great idleness and disorder during summer. [...] Yet the famous cathedral here, is but a melancholy dungeon, with all its riches and ornaments ${ }^{29}$.

Otros famosos viajeros mostraron imágenes más favorables del país que -sin estar exenta de tópicos- realzaban en mayor medida Galicia y sus gentes. Uno de los más conocidos fue Alexander Laborde, conde del Imperio francés y marqués de Laborde, escritor, viajero, arqueólogo y político francés, entre otras múltiples ocupaciones. De raíces españolas, luchó contra los ejércitos revolucionarios y regresó a Francia siguiendo a Napoleón. Como protegido de Luciano Bonaparte (así como de Carlos IV y Godoy) trabajó en la embajada de Madrid en 1800 y se

\footnotetext{
27 A. JARDINE, Letters ..., pág. 119.

${ }^{28}$ A. JARDINE, Letters ..., págs. 256.

${ }^{29}$ A. JARDINE, Letters ..., págs. 254-255.
} 
consagró a la edición de grandes libros sobre España ${ }^{30}$. En el año 1816 la librería de Cabrerizo publicó una traducción libre del Itinerario... de este escritor, incluyendo los mapas de acceso a Galicia ${ }^{31}$. En esta obra, el texto dedicado al reino de Galicia comenzaba con una descripción geográfica bucólica e ideal:

Su terreno, aunque muy montuoso, forma hermosos valles y vegas muy fértiles, y abunda en centeno, maíz, cebada, buen lino, cáñamo, legumbres, frutas muy deliciosas, y también vino en algunos parages. Sus deliciosos prados mantienen mucho ganado caballary vacuno. En los montes y país baxo hay muchas y preciosas minas, y aguas minerales, y bosques arbolados de encinas, robles y castaños, donde se crían osos, jabalies, liebres, perdices y otros animales ${ }^{32}$.

Al igual que Jardine (1788), el autor francés realizó una serie de apreciaciones sobre la naturaleza de los hombres y mujeres gallegos, plagada de clichés. Sin embargo, las cualidades que les atribuían reflejan una mejor consideración por parte de Laborde hacia los habitantes de la región:

Los antiguos habitantes de la Galicia se dedicaron mucho á la guerra y á la caza, y los más débiles á la pesca, mientras sus mujeres cultivaban las tierras, recogían las cosechas, y entendían en el gobierno doméstico; quando estas parían, sus maridos se metían en cama; costumbre que aun hoy día se supone observada en algunos puntos de la América meridional. Los gallegos de nuestros días están muy distantes de la barbarie de sus antepasados; sus costumbres sencillas y no corrompidas con ideas de luxo, les proporcionan donde quiera exercitar la hospitalidad. Libres de placeres desordenados, viven felices, bebiendo la leche de sus vacas, y comiendo cecina y pan de centeno, y nabos. [...] Son los mejores y más fieles sirvientes de todo el mundo, valientes soldados, y amantes de su

\footnotetext{
${ }^{30}$ Sus cuatro volúmenes del Voyage pittoresque et historique de l'Espagne, publicados entre $1806 \mathrm{y}$ 1820, ejercieron una gran influencia en Europa y fijaron una imagen de España como país pintoresco. Pero ninguna de sus páginas recoge impresiones sobre la Galicia del Antiguo Régimen.

${ }^{31}$ M. CABRERIZO, Itinerario descriptivo de las provincias de España y de sus islas y posesiones en el Mediterráneo; con una sucinta idea de su situación geográfica, población, historia civil y natural, agricultura, comercio, industria, hombres célebres, carácter y costumbres de sus habitantes, y otras noticias que amenizan su lectura. Traducción libre del que publicó en francés Mr. Alexandro Laborde en 1809. Acompaña un Atlas de 29 mapas, Valencia, Imprenta de Ildefonso Mompié, 1816, págs. $325-343$.

${ }^{32}$ M. CABrerizo, Itinerario..., pág. 325.
} 
religión y de su rey. Son graves, serios, y casi tristes, pero al mismo tiempo discretos, aunque poco amantes de la sociedad ${ }^{33}$.

Asimismo, encontramos referencias al flujo migratorio de los gallegos motivado por el sistema de propiedad de la tierra. La concentración de ésta en pocas manos, les obligaba habitualmente a acudir a las siegas en ambas Castillas y a ejercer el oficio de:

ganapanes ó mozos de cordel, y toda clase de servidumbre; en la qual se portan con tanta probidad y exactitud, que en breve se hacen dueños de la voluntad de sus amos, á los quales se someten hasta parecer sus esclavos; no por baxeza de alma, sino por una cierta bondad que les caracteriza ${ }^{34}$.

En todo caso, tras realizar una pequeña introducción histórica sobre los orígenes del reino de Galicia, Laborde ofrece una relación de los principales puertos, ríos y ciudades del mismo. Sin embargo, el tema omnipresente en este itinerario, como no podía ser de otra manera dado el título, se refiere a las principales rutas terrestres existentes en Galicia. A principios del siglo XIX, el texto recogía las siguientes:

Cuadro 1. Caminos en Galicia a principios del siglo XIX

\begin{tabular}{|l|l|}
\hline Astorga-Santiago & Pontevedra-Ourense \\
\hline Lugo-A Coruña & Vigo-Ourense \\
\hline Santiago-A Coruña & Santiago-Ourense \\
\hline A Coruña-Ferrol & Ourense-Requejo \\
\hline Santiago-Tui & Lugo-Mondoñedo \\
\hline Madrid-Santiago (camino de posta) & A Coruña-Ferrol-Ribadeo \\
\hline Tui-Ourense & \\
\hline
\end{tabular}

Fuente: M. CABRERIzo, Itinerario ..., págs. 325-343.

\footnotetext{
${ }_{33}$ M. CABrerizo, Itinerario..., pág. 343.

${ }^{34}$ M. CABRerizo, Itinerario..., págs. 340-341.
} 
Algunas de estas rutas son calificadas generosamente de buenas e incluso hermosas. Por ejemplo, el viajero francés califica el camino que une Santiago con A Coruña de muy hermoso y de agradable y divertido el de Santiago a Tui, en especial por los paisajes que atraviesan. Así, a pesar de las dificultades de acceso al reino desde Villafranca del Bierzo, su descripción resulta ilustrativa de una Galicia pintoresca:

\begin{abstract}
Al dexar el camino real se toma otro bastante incómodo, pero en él se disfruta de una país pintoresco, regado por un río sinuoso y arbolado de soberbios castaños. Pasado el lugar de Ferrerías, se trepan unas rocas escarpadas, y se atraviesa el puerto del Cebrero con el lugar de este nombre, famoso por los ricos quesos que en él se trabajan. De aqui se baxa al reyno de Galicia por el lugar de Fonfria hasta el de Gallegos, en donde se encuentra una posada llamada Mesón Real. Las campiñas, arboledas, cercas y pastos que se ven hasta llegar a Lugo, manifiestan desde luego el esmero de la agricultura en este reino ${ }^{35}$.
\end{abstract}

Desafortunadamente, aunque algunos caminos resultasen buenos, no se podía contar siempre con la presencia de posadas en diversos puntos del camino y aún en caso de que existiesen la limpieza no era un valor en alza. Así sucedía, por ejemplo, en los caminos que conectaban las villas marítimas del oeste gallego con Ourense donde terminaba la carretera Real de Madrid. Por otra parte, gran parte de las vías eran sólo transitables a caballo y extremadamente peligrosas como la costera que partiendo de A Coruña y Ferrol, llegaba hasta Ribadeo y conectaba con las regiones cantábricas ${ }^{36}$.

Este libro también tiene la virtud de presentar breves descripciones coloristas de las principales villas gallegas: A Coruña, Ferrol, Betanzos, Santiago, Tui, Baiona, Lugo, Mondoñedo, Ourense, Vigo, Pontevedra, Redondela, Ribadavia, Viveiro, Ribadeo y Noia que ocupan pequeños párrafos en sus páginas. El autor dibuja lo más notable de dichas poblaciones con pocas pinceladas. Así, a principios del siglo XIX, le llamaba todavía la atención los baños termales lucenses casi abandonados. Por otra parte, Santiago no había perdido la celebridad de antaño pese a que las peregrinaciones habían decaído desde mediados del siglo XVIII. La catedral de Santiago y la torre de Hércules coruñesa se cuentan entre los monumentos que destaca Laborde, así como el famoso cabo Finisterrae o la ría de Muros. Minas,

\footnotetext{
35 M. CABrerizo, Itinerario..., págs. 328.

${ }^{36}$ M. CABRERIzo, Itinerario..., págs. 339.
} 
comercio e industria son también objeto de interés para este forastero, así como las fortificaciones y defensas de cada ciudad. Así sucede en el caso del estratégico Ferrol, con astillero y arsenal. Recordemos que Laborde comienza su periplo por España poco antes de la invasión napoleónica por lo que su interés por las defensas, fortificaciones e industrias militares no resultaba banal.

Más entrado el Ochocientos, el británico Richard Ford $(1845)^{37}$, que recorrió España durante tres años, se aventuró a entrar en el primigenio reino de Galicia y ofreció una descripción pormenorizada de su paso por estas tierras. En particular, Ford relató que Galicia recibía pocas visitas -la mayoría de muleros- y sus caminos solían ser:

un continuo subir y bajar, cuesta arriba y cuesta abajo, y un constante transportar la mercancía y luego vadear: se progresa muy poco después de mucho trabajo, tanto para el hombre como para el animal.

No obstante, aconsejaba su visita durante los meses cálidos y alababa la bondad del paisaje y la abundante pesca. Richard Ford afirmaba que el río Miño atravesaba un paraíso de fertilidad y prestó atención especial a los baños minerales que jalonaron su periplo ${ }^{38}$. Asimismo, Santiago podía convertirse en un punto turístico de interés para todo aquel inglés que desease atravesar la península. En sintonía con Laborde, mostraba una descripción bucólica y colorista de la naturaleza gallega que divergía de la miseria del campesinado, habitantes en casas sucias y húmedas. También a Ford le llamó la atención el duro trabajo de las mujeres gallegas tanto en la casa como en el campo, donde empuñan el arado, mientras los hombres emigraban en busca de mejor fortuna. Como vemos, poco parecía haber cambiado en casi cuarenta años.

Sin embargo, Galicia se encontraba para Ford entre las peores zonas de la península desde el punto de vista de medios públicos de comunicación. Las vías en mejor estado eran los caminos Reales que comunicaban Madrid con los puertos de mar más notables, como A Coruña, aunque solían tenderse en línea recta o soslayaban las continuas cadenas de montañas. Por lo tanto, muchas de las antiguas ciudades quedaban fuera del trayecto en los puntos de difícil acceso,

\footnotetext{
${ }^{37}$ Richard FoRD, Manual para viajeros por España y lectores en casa. Observaciones generales sobre el país y sus ciudades, costumbres de sus habitantes, su religión y sus leyendas, las bellas artes, la literatura, los deportes, la gastronomía, y diversas noticias sobre su historia, Madrid, Turner, 1845, reedición de 1982.

${ }^{38}$ R. Ford, Manual..., págs. 204-218 y 256-259.
} 
donde sólo se podía llegar a caballo ${ }^{39}$. Por ejemplo, calificó las carreteras que conducían a Santiago de Compostela, uno de los puntos que podía suscitar mayor interés turístico, como detestables:

Los caminos de Galicia, a pesar de la protección de Santiago -sustituto del romano Hermes-, al igual que la Vía Láctea en el cielo tienen muy poco que agradecer a los cuidados humanos ${ }^{40}$.

Por tanto, los coches correo y las diligencias circulaban sólo por las carreteras principales, como la que unía A Coruña y Madrid. Escasos coches locales intercomunicaban las ciudades provinciales. Ford ofrecía una imagen de la comunidad en la que apenas había tráfico, por lo que la demanda de vehículos modernos resultaba inexistente. En consecuencia, nuestro incansable viajero tuvo que recorrer a caballo la región, aunque no siempre encontró mulas o caballos disponibles, suponemos que por estar ocupados en tareas agrarias. Pero los feos y bastos caballos gallegos resultaban insustituibles para aquella comarca montañosa y su laboriosa población; necesitaban poco cuidado y se satisfacían con cualquier clase de forraje y maíz:

Aún recordamos el horror de nuestro criado andaluz, la primera vez que llegamos a Galicia, cuando se precipitó en nuestra busca exclamando que los animales se morirían, pues no habia que darles de comer más que avena y heno ${ }^{41}$.

Durante los tumultuosos años de la primera guerra carlista, George Borrow, otro incansable viajero, aunque no se consideraba a sí mismo turista ni escritor de libros de viajes, dejó muestras de su fascinación por España y todas sus regiones en su obra The Bible in Spain, publicada en 1842 a resultas de una estancia intermitente en la península ibérica. Mientras Don Jorgito el inglés realizaba la tarea de divulgar el Nuevo Testamento en España, aprovechaba para visitar diversos lugares y escribir una serie de cartas en las que recogió sus experiencias desde su primera visita a nuestro país en 1835. Para este autor, los años que pasó allí fueron los más felices de su vida. Caracterizó a España como the land of wonder and mystery y the most magnificient country in the world, probably the most fer-

\footnotetext{
39 R. Ford, Manual..., pág. 115.

${ }^{40}$ R. Ford, Manual..., págs. 54-82.

${ }^{41}$ Richard Ford, Las cosas de España, Madrid, Turner, 1846, reedición de 1988, pág. 137.
} 
tile and certainly with the finest climate. En paralelo, dedicó a Galicia casi siete capítulos de su libro, lo que refleja, además de una estancia más prolongada, un interés muy superior al del cronista medio ${ }^{42}$.

Al igual que Ford entró por Pedrafita y nos regaló unas pintorescas descripciones del paisaje, más amplias y literarias que las del primero. La naturaleza gallega, sus gentes, el lenguaje, sus principales ciudades, sus baños termales así como diversas anécdotas salpican a menudo sus capítulos. La majestuosidad del paisaje, la dureza de la costa gallega en torno al Cabo Finisterre y la miseria de sus gentes quedaron retratados en sus páginas.

The villages were mostly an assemblage of wretched cabins; the roofs were thatched, dank, and moist, and not unfrequently covered with rank vegetation. There were dunghills before the doors, and no lack of pools and puddles. Immense swine were stalking about, intermingled with naked children. The interior of the cabins corresponded with their external appearance: they were filled with filth and misery ${ }^{43}$.

Esta pobreza impregnaba las calles ferrolanas plagadas de mendigos y pedigüeños ante la decadencia del Arsenal:

Sadness came upon me as soon as I entered this place. Grass was growing in the streets, and misery and distress stared me in the face on every side. Ferrol is the grand naval arsenal of Spain, and has shared in the ruin of the once splendid Spanish navy: it is no longer thronged with those thousand shipwrights who prepared for sea the tremendous three-deckers and long frigates, the greater part of which were destroyed at Trafalgar. Only a few ill-paid and half-starved workmen still linger about, scarcely sufficient to repair any guarda costa which may put in dismantled by the fire of some English smuggling schooner from Gibraltar. Half the inhabitants of Ferrol beg their bread; and amongst these, as it is said, are not unfrequently found retired naval officers, many of them maimed or otherwise wounded, who are left to pine in indigence; their pensions

\footnotetext{
${ }^{42}$ George. H. Borrow, The Bible in Spain or The Journeys, Adventures, and Imprisonments of an Englishman, in an Attempt to circulate the Scriptures in the Peninsula, London, Paris, New York, Toronto and Melbourne, Cassell and Company, Ltd., 1842, reedición de 1908, pág. 36.

${ }^{43}$ George. H. Borrow, The Bible..., pág. 155.
} 
or salaries having been allowed to run three or four years in arrear, owing to the exigencies of the times ${ }^{44}$.

Borrow recorrió sobre todo diversas poblaciones de la zona atlántica y cantábrica gallega: A Coruña, Santiago de Compostela, Finisterre, Padrón, Pontevedra, Vigo, Viveiro y Ribadeo a las que sumaríamos Lugo, situada en el camino Real hacia A Coruña. En cambio, Ourense y otras poblaciones más interiores -y alejadas de los principales caminos- no entraron en su hoja de ruta. Salvando el trayecto que realizó en barco entre A Coruña y Ferrol, como muchos otros se vio obligado a recorrer Galicia a lomos de un equino. En paralelo, el alojamiento tanto para humanos como para animales resultaba una dificultad añadida. A veces encontraba posadas o fondas en las que alojarse. Pocas destacaban por su calidad y/o salubridad. Otras veces debía pasar la noche en las chozas de los naturales del país ante la ausencia de hospedaje de ninguna clase.

En conjunto, los relatos de estos cuatro viajeros durante su periplo gallego comparten algunos rasgos: descripciones de los paisajes que transitan y las gentes que habitan en el lugar, opiniones de tipo económico sobre el territorio en cuestión, comentarios sobre los accesos terrestres al mismo (en algún caso, como Laborde -el que mejor se aproxima probablemente a una guía de viaje actual-, detallando y midiendo los itinerarios de viaje) e indicaciones sobre las principales poblaciones de la región y lo más llamativo que pudiese atraer al futuro visitante.

Entre estas observaciones destacaríamos por un lado las de tipo económico. A este respecto, los relatos de viajeros no iban demasiado desencaminados. La realidad gallega de la época apoya la mayoría de sus conclusiones. La economía de Galicia mantuvo un carácter tradicional y preindustrial durante los siglos XVIII y XIX. Hacia finales del Setecientos, el crecimiento de la población y los recursos agrarios gallegos auguraban un futuro prometedor para la comunidad. Se trataba de una de las regiones españolas más densamente pobladas donde la agricultura mantenía rasgos propios de una economía de subsistencia aunque había experimentado pequeños cambios relacionados con la difusión del maíz y la patata. De hecho, las nuevas roturaciones condujeron a un crecimiento agrario considerable, pero la productividad agraria gallega seguía siendo baja y el minifundismo persistente. El sistema de tenencia de la tierra estaba condicionado por la singularidad del foro y los campesinos complementaban sus ingresos agrarios con actividades de auxilio como la extendida producción doméstica de lienzos, la pesca y la salazón, la manufactura rural del hierro o la fabricación de curtidos, entre otras. Desde el punto de vista mercantil, el territorio se incorporó a los lucrativos

${ }^{44}$ G. H. Borrow, The Bible..., pág. 196. 
circuitos comerciales con las colonias americanas lo que benefició especialmente a puertos como A Coruña, Vigo y Carril ${ }^{45}$. Según indica Alonso Álvarez (1986 y 2005), en tiempos de Carlos III un secretario del Consejo de Castilla llegó a proponer al reino de Galicia como el paradigma del Antiguo Régimen y ejemplo a imitar por el resto de España ${ }^{46}$. Pero con el despertar del siglo XIX comienza la desarticulación de esta economía tradicional sin el acompañamiento paralelo de un proceso industrializador. El sector agrario se encaminó tímidamente por la senda del mercado pero no evitó la caída de la renta y la población galaica frente al conjunto nacional. Tampoco surgió una burguesía capaz de modernizar la estructura agraria gallega, convirtiéndola así en la base del desarrollo capitalista autóctono. A la muerte de Fernando VII, las reformas liberales alteraron el sistema institucional vigente hasta entonces pero en Galicia apenas se produjeron transformaciones sustanciales. Como consecuencia, las relaciones forales y el minifundismo se mantuvieron como rasgos básicos de su agricultura durante el Ochocientos. Desafortunadamente, la decadencia de la industria rural doméstica privó de una fuente de renta notable a los campesinos. El sector agrario resultó incapaz de sostener el crecimiento demográfico y muchos pasaron a engrosar las filas de la emigración americana, especialmente hacia el último cuarto del siglo XIX ${ }^{47}$. Éste fue el territorio que se encontraron nuestros primeros cronistas forasteros a finales del siglo XVIII y en las primeras décadas del siglo XIX. No creemos que esta situación socioeconómica desincentivase por sí misma los viajes a la región. A este respecto España tampoco gozaba en conjunto de una situación económica mucho más avanzada. En cambio, sí podía afectar al desarrollo de infraestructuras u otros medios que facilitasen la accesibilidad turística (medios de transporte, alojamiento, desarrollo de centros de ocio, etc.). En todo caso, los testimonios disponibles parecen apuntar que el desconocimiento del territorio y el alejamiento de las principales -e incipientes- rutas turísticas europeas pesaba más en el ánimo de la clientela potencial.

Por otro lado, también destacaríamos aquellas observaciones viajeras que remarcaban lo que denominaríamos hoy en día una serie de puntos de interés turístico -sus principales ciudades con Santiago de Compostela, A Coruña y

\footnotetext{
${ }^{45}$ Con el fin de ampliar la evolución demográfica y económica de Galicia en el Antiguo Régimen, véanse por ejemplo Pegerto SaAvedra, La Galicia del Antiguo Régimen. Economía y Sociedad, A Coruña, Hércules, 1991, Xosé Ramón Barreiro Fernández y Ramón Villares Paz (coord.), A Gran Historia de Galicia, A Coruña, La Voz de Galicia, 2007, vols. 11 y 12 e Isidro Dubert (coord.), Historia de la Galicia Moderna, Santiago de Compostela, Servicio de Publicaciones de la USC, 2012. ${ }^{46}$ Luis Alonso Álvarez, Comercio colonial y crisis del Antiguo Régimen en Galicia (1778-1818), A Coruña, Xunta de Galicia, 1986, pág. 54 y Luis Alonso Álvarez, "La crisis de la economía tradicional: continuidad y cambio en la Galicia del siglo XIX", en J. de Juana y J. Prada (coords.), Historia contemporánea de Galicia, Barcelona, Ariel, 2005, págs. 33-55.

${ }^{47}$ Xoán Carmona, El atraso industrial de Galicia, 1750-1900, Barcelona, Ariel, 1990, págs. 235-236.
} 
Ferrol en primera línea, los baños minero-medicinales (inmersos en un proceso de redescubrimiento $)^{48}$ y la Costa da Morte-, y aquellas narraciones que nos obsequiaban con estampas de las infraestructuras viarias, que confirman el mal estado de los caminos gallegos y/o las enormes dificultades que debían salvar estos aventureros en la región noroeste de la península. En este sentido, también ponían de manifiesto las diferencias en el acceso entre las poblaciones de la costa y las del interior gallego, lo que redundaba en un aislamiento y desconocimiento mayor. En definitiva, sea intencionadamente o no, estos testimonios ofrecen en ocasiones qué ver y cómo acceder a Galicia, información clave para el futuro turista. Precisamente, de los accesos, en especial terrestres, nos ocuparemos en el siguiente epígrafe.

\section{Galicia y las COMUNICACIONES TERRESTRES PRE-FERROVIARIAS: UN PANO- RAMA GENERAL}

En la España de los siglos XVI y XVII, la dinastía Habsburgo apenas mostró interés por la mejora de los caminos y las vías de comunicación terrestres. En cambio, con la llegada de los Borbones a principios del siglo XVIII, se promulgaron una serie de medidas encaminadas a mejorar el estado de los caminos y a fomentar el tráfico de mercancías interregional. La Instrucción de Intendentes de 4 de julio de 1718 y, sobre todo, la Ordenanza de Intendentes de 13 de octubre de 1749 respondieron a este nuevo interés por parte de la monarquía ${ }^{49}$. Sin embargo, los proyectos camineros se retrasaron hasta mediados del siglo XVIII. De hecho, la legislación estatal sobre carreteras pavimentadas en España no despegó hasta el 10 de junio de 1761 con el Real Decreto expedido para hacer Caminos rectos, y sólidos en España, que faciliten el comercio de unas provincias a otras, dando principio por las de Andalucía, Cataluña, Galicia y Valencia ${ }^{50}$. La normativa se centró en la necesidad de construir caminos rectos y sólidos bajo una estructura centralizada y radial, sostenida en criterios más políticos que económicos. Bajo estas pautas, el texto legal estableció como prioridad la construcción de caminos que partiesen de la Corte, frente a los caminos interprovinciales y los que servían de enlace entre varios pueblos ${ }^{51}$.

\footnotetext{
${ }^{48}$ L. Alonso Alvarez, E. Lindoso Tato y M. Vilar Rodríguez, O lecer...

${ }^{49}$ Santos Madrazo, El sistema de transportes en España, 1750-1850, Madrid, Ediciones Turner, vol. 1, 1984, págs. 95-96.

${ }^{50}$ S. MADRAZo, El sistema ..., págs. 95-96. El Decreto fue acompañado por un Reglamento aprobado el 2 de diciembre de 1761 que pretendía dar impulso a las obras.

${ }^{51}$ Manuel García-Fuentes, Galicia incomunicada por red viaria en el siglo XVIII, A Coruña, Servicio de Publicaciones de la Universidad de A Coruña, 1999, pp. 27-32.
} 
Ante los limitados recursos públicos, se decidió que la financiación correría a cargo del sobreprecio de dos reales de vellón en cada fanega de sal consumida. Se estimó que la asignación anual ascendería a tres millones de reales de los que la quinta parte se destinaría a Galicia y el resto se repartiría a partes iguales entre Andalucía y Cataluña ${ }^{52}$. Sin embargo, a pesar del creciente flujo de recursos procedentes de las tesorerías americanas, la Hacienda española presentaba enormes dificultades para financiar el gasto público ${ }^{53}$. Así, el desarrollo de la red viaria vino marcado en las últimas décadas del Setecientos por la lentitud de las obras y los elevados costes para las debilitadas arcas de la Hacienda Real ${ }^{54}$. Pero el interés por mejorar las comunicaciones terrestres no cesó. En el ocaso de la centuria, la Ordenanza general de correos, postas y caminos (1794) trató de poner orden en la legislación vigente y solucionar los problemas pendientes, sobre todo las dificultades técnicas, - con la creación del Cuerpo y Escuela de Ingenieros de Caminos- ${ }^{55}$, y las carencias financieras, más difíciles de resolver en un periodo de crisis económica y elevados gastos bélicos. Hay que considerar que, entre 1793 y 1808, España estuvo casi de manera permanente en guerra con Francia e Inglaterra. A esto se le sumó el estallido de la Guerra de la Independencia (1808-1814) que supuso el abandono de los proyectos estatales, el cierre de la mencionada escuela y el deterioro de las infraestructuras del país.

Una vez terminado el conflicto, en el marco del Trienio Liberal se elaboró la Memoria de Caminos y Canales (1820), documento que introdujo normativas técnicas, en cuanto a la cualificación del personal y a la ejecución y a la calidad de las obras, pero también aportó novedades en la clasificación de las carreteras, delimitó las competencias de los distintos organismos públicos en la ejecución y la conservación de los caminos y estableció las bases para una financiación capitalista del ramo. El regreso al trono de Fernando vil en 1823 puso en cuarentena la filosofía liberal en el ámbito de las infraestructuras y comunicaciones. No

\footnotetext{
${ }^{52} \mathrm{Si}$ las obras lo exigían, existía la posibilidad de aumentar hasta tres reales en fanegas de sal consumidas en Galicia. Entre 1761 y 1793, el producto del arbitrio gallego sumó 19.391 .174 reales y 33 maravedíes. La recaudación sirvió para sufragar los gastos de la construcción del camino A Coruña-Astorga e incluso alcanzó para financiar parcialmente el realizado entre Asturias y León, véase M. García-Fuentes, Galicia ..., págs. 32-38, 103-104.

${ }^{53}$ Enrique Llopis, "La crisis del Antiguo Régimen y la Revolución Liberal (1790-1840)", en Comín, F., Hernández, M. y Llopis, E. (eds.), Historia Económica de España, siglos X-XX, Barcelona, Crítica, 2002.

${ }^{54}$ F. de P. Mellado, Guía de viajero en España, Madrid, Establecimiento tipográfico, 1849.

${ }^{55}$ España no experimentó grandes cambios en su sistema de comunicaciones hasta la década de 1840 cuando el Cuerpo de Ingenieros de Caminos quedó ya plenamente establecido gracias al Reglamento de 1836. En 1833, se creó la Dirección General de Caminos y en 1834 la Escuela de Ingenieros de Caminos. Tras la promulgación del Reglamento de 1836, apareció la Junta Consultiva de Caminos, Canales y Puertos, véase Carlos Larrinaga, "Aproximación biográfica al Ingeniero de Caminos del siglo XIX, Manuel Peironcely”, Revista de Obras Públicas, 3.468 (2006), págs. 49-56.
} 
obstante, se restauraron viejas carreteras y se terminaron otras nuevas sufragadas con los ingresos postales, las contribuciones locales y el producto de los portazgos y barcas. La muerte del monarca y la quiebra del Antiguo Régimen introdujeron un soplo de aire fresco en las políticas de obras públicas. Sin embargo, el estallido de la primera guerra carlista quebró las previsiones y agravó los problemas hacendísticos. A partir de los años cuarenta, tras el triunfo del liberalismo, asistimos a la publicación de una prolija legislación sobre la clasificación y conservación de los caminos existentes, la preocupación por los trazados y las necesidades de construcción de otros nuevos ${ }^{56}$.

Hubo dos grandes novedades en este periodo. En primer lugar, el Real Decreto de 19 de febrero de 1834 integró los gastos de las obras públicas en las atenciones presupuestarias del Estado, lo que supuso un hito en la construcción de un sistema nacional de comunicaciones ${ }^{57}$. Más tarde, la ley de 7 de mayo de 1851 , impulsada por el ministro Fermín Arteta, estableció una nueva clasificación de carreteras en cuatro apartados, según se atribuyese la competencia al Estado, a las provincias o a los pueblos ${ }^{58}$. Se denominaron carreteras "generales" aquéllas que partían de Madrid hacia las capitales de provincias, los departamentos marítimos y las aduanas de gran movimiento mercantil, junto con los ramales que ordenaba construir y financiaba el gobierno. En el grupo de carreteras "transversales" quedaron clasificados los enlaces entre las carreteras generales que atravesaban una capital de provincia o núcleos de abundante población, cuya financiación se repartían el gobierno (entre un tercio y la mitad) y las provincias. Las carreteras "provinciales" servían de enlace entre las dos anteriores o comunicaban varias provincias y las "locales" se referían a los caminos de los pueblos. La construcción y el mantenimiento de las dos últimas modalidades quedaban a cargo de los recursos aportados por las diputaciones y los ayuntamientos, aunque el gobierno podía subvencionar las vías provinciales hasta con un tercio de su coste total. Para estos fines, las diputaciones contaban con los productos de los portazgos, pontazgos y barcajes procedentes del tráfico de las carreteras provinciales. Mientras tanto, el estado de las carreteras locales dependía de los escasos recursos de los municipios, las asociaciones culturales y benéficas privadas y las donaciones filantrópicas. En general, las preocupaciones de los responsables del impulso de las infraestructuras giraron en torno a dos elementos esenciales: el trazado de la red de carreteras y las necesidades presupuestarias para ejecutar las obras.

Dentro del marco general descrito, el estado de los caminos variaba según las regiones. En su conocido trabajo sobre los transportes y el estancamiento eco-

\footnotetext{
${ }^{56}$ S. MADRAZO, El sistema ..., pág. 102. Este autor señala que, entre 1833 y 1859, se aprobaron 2.972 disposiciones legales sobre normativa de obras públicas.

${ }^{57}$ Gaceta de Madrid de 20 de febrero de 1834, núm. 23.

${ }^{58}$ Gaceta de Madrid de 13 de mayo de 1851, núm. 6147.
} 
nómico en España entre 1750 y 1850, Ringrose dejó de manera voluntaria fuera de su análisis cuantitativo a Galicia porque, según comentaba, era una región aislada de Castilla en plena mitad del siglo XVIII y sus contactos terrestres con el exterior se restringían a los transportadores de la provincia de León ${ }^{59}$. Por su parte, Madrazo sentenciaba al comenzar su estudio sobre las comunicaciones terrestres en el ecuador de la misma centuria que las dificultades orográficas no permitían el tráfico rodado entre Galicia y Castilla ${ }^{60}$. Como consecuencia, los pocos caminos y el mal estado de los disponibles obligaban a utilizar el transporte a lomo, lo que suponía mayor peligrosidad para viajeros y animales y un mayor coste de los portes. Escritos de la época, como el Itinerario Español o Guía de Caminos de Escribano de 1758, constataban la ausencia de caminos de ruedas o carreteros para llegar desde Castilla a Galicia, pues la vía procedente de Madrid finalizaba en Astorga. Debemos considerar que algunos tramos de los caminos de herradura podían usarse para el tráfico rodado, pero en los trechos más pendientes los carros o carretas cargados de mercancías necesitaban la ayuda de más animales de tiro $^{61}$. En general, los viajes largos continuaron haciéndose a caballo y a pie hasta mediados del siglo XVIII -e incluso más entrado el siglo XIX, tal y como hemos visto en los anteriores testimonios de los viajeros-, ya que Galicia resultaba inaccesible al transporte rodado desde el exterior. De hecho, en el sistema radial de carreteras ideado por la monarquía borbónica, el ramal gallego era el único que no llegaba a la costa, lo que dejaba en evidencia el aislamiento rodado de Galicia.

Por entonces, un grupo de ilustrados gallegos como Cornide o Labrada reclamaron en la Corte una mejora de las comunicaciones que pusiera fin a este aislamiento con respecto al resto de la península. En paralelo, demandaron la habilitación de pasos interiores por donde pudieran transitar los carruajes de personas y el tráfico de mercancías interprovincial ${ }^{62}$. Los caminos transversales y vecinales desempeñaban un papel fundamental en el tráfico interior de mercancías. Consciente de este hecho, el Conde de Floridablanca encargó al diputado nacional de caminos, el ilustrado José Cornide, la elaboración de un informe sobre el estado de los puentes y los caminos secundarios del Reino de Galicia a

\footnotetext{
${ }^{59}$ D. Ringrose, Los transportes y el estancamiento economicos de España (1750-1850), Madrid, Ed. Tecnos, 1972, pág. 117. El autor hace referencia a los arrieros maragatos, uno de los principales grupos de transportistas de la época, cuyo centro de operaciones radicó en San Román cerca de Astorga, véanse las obras de Laureano RuBIo PÉREz, Arrieros maragatos: poder, negocio, linaje y familia, siglos XVI-XIX, León, Fundación Hullera Vasco-Leonesa, 1995 y La burguesía maragata: dimensión social, comercio y capital en la corona de Castilla durante la Edad Moderna, León, Universidad Secretariado de Publicaciones, 1995.

${ }^{60} \mathrm{~S}$. Madrazo, El sistema ..., pág. 238.

${ }^{61}$ X. Barreiro, "O atraso económico e o sistema de transporte terrestre na Galicia do século XIX", Revista Galega de Economia, X, 1 (2001), págs. 71 y ss.

${ }^{62}$ M. García-Fuentes, Galicia ..., págs. 32-38.
} 
finales del Setecientos. El comisionado recorrió más de 300 leguas a lo largo y ancho del territorio ${ }^{63}$. Como resultado de sus minuciosas observaciones, realizó un diagnóstico de las vías de comunicación de la provincia de Santiago. En su trabajo concluyó que de la capital del reino de Galicia entraban y salían varios caminos públicos que vienen no sólo de Castilla sino de las otras provincias y pasan a las costas facilitando el mutuo comercio de las producciones de éstas y de aquéllas, dando paso a las tropas y los viajeros. La principal función de este trazado consistía en comunicar las ferias celebradas en cada pueblo con el mercado central de Santiago para facilitar la movilización y la comercialización de los productos en su área de influencia. Sin embargo, los proyectos de construcción de carreteras que se aprobaron posteriormente favorecieron las comunicaciones del puerto coruñés con Madrid, mientras que las carreteras transversales se convirtieron en un objetivo secundario.

La financiación no resultaba una cuestión baladí. Tal y como mencionamos anteriormente, hacia mediados del Setecientos, la financiación de la construcción de carreteras recayó sobre todo en los impuestos sobre consumos, cuya recaudación resultaba escasa en Galicia, debido a los bajos niveles de comercialización de productos y al elevado autoconsumo de la población. De esta manera, los municipios y los particulares sobre los que recaía la responsabilidad de la adaptación al tráfico rodado no podían acometer la transformación de la red, lo que se traducía en unas mejoras limitadas. La situación preocupó al marqués de la Ensenada, bajo cuyo ministerio se proyectó la carretera de Madrid hacia A Coruña. El tramo entre esta ciudad y Benavente comenzó a construirse en 1761 para convertirse en el eje de las comunicaciones gallegas ${ }^{64}$. No obstante, el trazado del camino real a Galicia suscitó un debate entre los ilustrados de la época, unos tomaban partido por el considerado como camino "oficial" entre Benavente y A Coruña y otros defendían la ruta sur entre Benavente y Vigo ${ }^{65}$.

La Corona optó por la ruta norte, más acorde con sus intereses políticos de enlazar el puerto coruñés con la Corte ${ }^{66}$. La ciudad de A Coruña aunaba muchos intereses políticos y empresariales, pues su puerto había sido elegido como sede de los Correos Marítimos desde 1764 y habilitado para el comercio colonial en 1765. Tampoco podemos olvidar que en la ciudad coruñesa estaba situada la Capitanía General, la Real Audiencia y, más tarde, en 1785, el Real Consulado. Todos estos organismos y las sociedades económicas de amigos del país de San-

\footnotetext{
${ }^{63}$ Archivo del Reino de Galicia (ARG), Informe de los caminos de Galicia presentado por D. José Andrés Cornide, leg. 13, $\mathrm{n}^{\circ} 216$.

${ }^{64}$ Fausto Dopico y X. BARReiro, "Os camiños da provincia de Santiago. Introducción ao estudo do transporte na Galicia do Antigo Réxime”, Revista del Museo de Pontevedra, XXXII (1978), págs. 1-19. ${ }^{65} \mathrm{~S}$. MAdRAZo, El sistema ..., pág. 243.

${ }^{66}$ M. García-Fuentes, Galicia ..., págs. 17-27.
} 
tiago y Lugo, junto con la importancia estratégica desde el punto de vista militar del cercano puerto de Ferrol, colaboraron en el éxito de la propuesta oficial y despreciaron las ventajas técnicas y las demandas económicas y productivas del acceso sur, que transcurría por territorios más poblados y prósperos ${ }^{67}$. Más adelante, los representantes políticos de las provincias del norte presionaron para que los escasos fondos monetarios disponibles se destinasen a la construcción de enlaces transversales que partían del camino norte hacia los territorios del sur y retrasaron en la medida de lo posible el acceso sur de Galicia a la Meseta. La situación dio lugar a un largo debate político, detrás del que se escondía una rivalidad entre los puertos de Vigo y A Coruña, por convertirse en principal entrada norte del comercio colonial:

los reyes solo han abierto una carretera desde Astorga hasta la Coruña por el país más esteril, sin duda con el solo objeto de conducir por ella trenes de artillería o los tesoros de la América a la Corte: dos Arzobispos gallegos dignos de los mayores elogios, los señores Rajoy y Malvar, han construido un camino hermoso desde la Coruña hasta el Puente S. Payo; por lo demás Galicia se halla en el estado primitivo de la naturaleza. Se ha mirado hasta aquí con bárbara indiferencia que fuese o no comunicable el mejor puerto de la España, como lo considera el sabio Jovellanos en su informe sobre la ley agraria, el famoso Vigo, con el país más pingüe de la Europa, quales son las riberas del Sil, del Miño y del Avia ;Fatales siglos ${ }^{168}$.

El trazado de la carretera general A Coruña-Astorga se ejecutó en varias fa$\operatorname{ses}^{69}$. Las obras se iniciaron en julio de 1763 y a comienzos de la década de 1770 se abordaron los tramos más costosos técnicamente en las inmediaciones de los puertos de Pedrafita, del Manzanal y de O Cereixal, cerca de Becerreá. Pero, los

\footnotetext{
${ }^{67}$ M. María Artaza Montero, "Vicente Vázquez del Viso y el acceso sur de Galicia a la Meseta, clave del desarrollo de Vigo", en Castrelos III-IV (1990-1991), págs. 319-324.

${ }^{68}$ Introducción a la obra J. F. SuÁrez FreYre, Viage de Galicia desde la Villa de Benavente o breve descripción de sus dos carreteras: de la construida desde Astorga a La Coruña y de la que debe construirse desde la villa de Benavente a la ciudad de Orense, Santiago y Vigo con algunas observaciones acerca de las obras, utilidad y circunstancias de cada una, Santiago, Ed. Oficina de D. Manuel Antonio Rey, 1813.

${ }^{69}$ Antes de la construcción del camino real Madrid-A Coruña, el acceso a Galicia se producía por el anteriormente mencionado camino medieval de Santiago, también conocido como camino francés. La alternativa era el camino medieval que entraba por el valle del Sil, véase C. NARDIZ, El territorio y los caminos en Galicia. Planos históricos de la red viaria, A Coruña, Xunta de Galicia, 1992, pág. 246.
} 
defectos de construcción obligaron a ejecutar diversas obras de reparación en varios puntos del trayecto lo que dilató el proyecto y sus costes. Por último, entre los años 1777 y 1785, se ejecutaron los últimos tramos de enlace entre Becerreá, Lugo y Betanzos. De hecho, resulta complicado fijar una fecha exacta de finalización del camino Real porque quedaron flecos pendientes y hubo que rehacer algunos trechos varias veces ${ }^{70}$. El mantenimiento de la calzada resultaba oneroso debido a la orografía y climatología gallega: suelo muy accidentado, abundancia de corrientes de agua y clima muy lluvioso que deterioraba rápidamente los trayectos recién construidos. Hasta mediados del siglo XIX, no se empezaron a construir casetas de peones camineros encargados de la conservación y la reparación de las carreteras ${ }^{71}$.

Además del camino general, se impulsaron dos carreteras provinciales en Galicia durante la segunda mitad del siglo XVIII: A Coruña-Santiago y Santiago-Tui ${ }^{72}$. De este modo, recién estrenado el siglo XIX, Galicia sólo disponía de dos caminos, las rutas A Coruña-Betanzos-Lugo-Madrid y A Coruña-Santiago-Pontevedra-Tui que, sin mostrar condiciones óptimas para el tráfico rodado, resultaban bastante aptos para distintos medios de transporte ${ }^{73}$. El resto de itinerarios discurrían por vías en mal estado, con firme encharcado, donde faltaban puentes imprescindibles, lo que obligaba al viajero a salvar corrientes de agua o a dar largos rodeos, y sobraban cuestas imposibles de subir.

El ansiado proyecto de una carretera que comunicase el sur gallego con la meseta estaba todavía pendiente de ejecución a finales del siglo XVIII tras varios intentos fallidos ${ }^{74}$. La Real Orden de 18 de junio de 1803 mandó construir

\footnotetext{
${ }^{70}$ Una Real Cédula de 1772 reglamentó la conservación de los caminos generales recién construidos. En cualquier caso, dadas las numerosas reparaciones, no se puede datar de forma definitiva la conclusión de las obras del camino real gallego, véase M. García-Fuentes, Galicia ..., págs. 81-88. ${ }^{71}$ F. Dopico y X. Barreiro, “Os camiños...”, págs. 1-19 y C. NARdiz, El territorio ..., pág. 236.

${ }^{72}$ M. GarCía-Fuentes, Galicia ..., págs. 105-132. Una antigua vía terrestre conocida como el camino de Faro, la ruta de los peregrinos, el camino francés de Poulo o el camino real de A Coruña a Santiago unía estas dos últimas poblaciones. Se decidió trazar la nueva carretera por el mismo lugar, Monelos, por donde transcurría el camino antiguo. En principio, se hizo coincidir con el antiguo Camino Real de la época de los Austrias. F. Urgorri y L. Fembiella, El Antiguo Camino Real de La Coruña a Santiago: el Camino de Faro o Camino Francés de Poulo, A Coruña, Fundación Caixa Galicia, 1992, págs. 7-27. Los autores señalan otras vías alternativas antiguas en página 51 y siguientes.

${ }^{73}$ F. Dopico y X. Barreiro, “Os camiños...”, págs. 1-19.

${ }^{74}$ Según las órdenes de 3 de marzo de 1789 y de 18 de marzo de 1795. Véanse Memoria sobre la necesidad de construir las carreteras provinciales de Santiago a Orense y de Santiago a Lugo, en el antiguo reino de Galicia, Madrid, Est. Tip. de H. Martínez, 1850 y C. NARDIZ, El territorio..., págs. 268-269. Para ampliar la visión sobre el estado de los caminos gallegos, recomendamos también la lectura de M. María de Artaza Montero, "La Junta del Reino y las carreteras de Galicia, 17751834", Revista del Instituto “José Cornide” de Estudios Coruñeses, año XXII, núm. 22 (1986), págs. 243-251; Isidro GARCía TATO, "Proyecto de reparación y modificación de trazado del camino real
} 
un camino de Benavente a Vigo pasando por Puebla de Sanabria y Monterrei, con hijuelas en Santiago y Tui y la villa de Pontevedra ${ }^{75}$. La esperada obra fue confiada al religioso de alta cuna Pedro Acuña y Malvar, designado secretario de Estado y del Despacho Universal de Gracia y Justicia bajo la presidencia del conde de Aranda. Para su construcción se destinaron otra vez los impuestos aplicados sobre el producto de la sal y además se consignó un nuevo gravamen para la construcción de un camino entre el puerto de Ferrol y Castilla, concebido como un desvío en Rábade de la carretera general entre A Coruña-Madrid. El nuevo tramo pasaba por Vilalba, As Pontes de García Rodríguez, Neda y Ferrol. En paralelo, desde Vilalba se proyectó otro ramal hacia la cornisa cantábrica que atravesaba la villa de Mondoñedo ${ }^{76}$.

Buena parte de estos proyectos quedaron suspendidos por la Guerra de la Independencia y se retrasó su ejecución. Respecto al camino sur de Galicia, hubo que esperar hasta el Real Decreto de 30 de marzo de 1833 para proseguir las obras. La nueva normativa asignó una serie de arbitrios para su construcción, entre ellos el de 2 reales y 18 maravedís en fanega de sal que se señalaron para los caminos transversales, y las obras comenzaron de manera oficial en julio de 1834. Trece años después, no habían concluido y la Diputación Provincial de Ourense urgía rematar la carretera con sus ramales a Santiago, Lugo y Valdeorras ${ }^{77}$. En 1846, el ingeniero jefe del distrito de A Coruña informaba sobre la conveniencia de dicho camino y proponía también la construcción del ramal de Ferrol a Ponte Rábade y posteriormente el de Lugo a Santiago. Además, los representantes políticos de las provincias de Pontevedra y Ourense mostraban su interés por la construcción del ramal Santiago-Ourense ${ }^{78}$. Los intereses provinciales eran diversos, mientras Pontevedra pretendía dar "vida a las feraces campiñas de su parte oriental", Ourense perseguía:

a su paso por Valdeorras, 1775-1805", en Actas de la Semana de Historia de Valdeorras, O Barco de Valdeorras, Instituto de Estudios Valdeorreses, 1998, págs. 97-158; Juan E. GelaberT GonZÁLEz, "Aspectos del sistema de transporte entre Galicia y Castilla en los siglos XVII y XVIII", Archivos Leoneses, 63 (1978), págs. 109-126 y Hortensio SoBrado CorREA, "Obstáculos estructurales al desarrollo de los intercambios comerciales en la Galicia de la Edad Moderna", Obradoiro de Historia Moderna, 17 (2008), págs. 303-324.

${ }^{75}$ J. Lucas Labrada, Descripción Económica del Reyno de Galicia por la Junta de Gobierno del Real Consulado de la Coruña, 1804, pág. 119.

${ }^{76}$ C. NARDiz, El territorio..., págs. 236.

${ }^{77}$ Su ejecución con planos adecuados tuvo lugar tras 1857, véase C. NARDIZ, El territorio..., págs. 246 y $268-269$. Las obras llegaron a Rivadavia en 1845 , conectando la villa con el puerto vigués donde conducían sus excelentes vinos. Los vinos de Ribadavia se dirigían también a Pontevedra a través de la carretera Rivadavia-O Carballiño, pero ésta inició su construcción en 1852 y no finalizó hasta 1886, véase Luis Domínguez CAstro, Viños, viñas e xentes do Ribeiro. Economía e patrimonio familiar, 1810-1952, Vigo, Xerais, 1992, págs. 130-131.

${ }^{78}$ Memoria sobre la necesidad..., págs.6-7. 
fomentar su más rica y abundante producción, como los vinos de Monterrey, cañada del Miño, Ribero de Abia y otros puntos que tendrán seguro despacho en la provincia de la Coruña, a donde a tanta costa llega dicho artículo con gran consumo por el porteo a lomo y malísimos caminos; y los sobrantes en unión con los celebrados jamones de Caldelas, tendrán segura salida por los puertos del Océano, viniendo a ser por otra parte dicho ramal la única y más central de ruedas para la comunicación de la provincia de la Coruña con la de Orense y viceversa ${ }^{79}$.

Tras la primera guerra carlista, principiaron los proyectos y la construcción de las carreteras de Betanzos a Ferrol, de Santiago a Lugo y de Santiago a Ourense ${ }^{80}$. Pero la mejora de algunos ramales fue objeto de la lucha de intereses localistas ${ }^{81}$. Así, todavía a mediados del siglo XIX, Mellado (1850) presentaba los caminos gallegos como:

muy malos y dificiles, con el peligro de los salteadores, que abundan bastante en Galicia, por las muchas gargantas, encrucijadas y espesuras que en el terreno se encuentran a cada paso, y por la cercanía a Portugal, donde se ocultan los malhechores en cuanto perpetran un robo, burlando la persecución de las tropas ${ }^{82}$.

Sin embargo, había algunas hermosas carreteras construidas con el mayor lujo y citaba como ejemplo la que desde A Coruña atravesaba Santiago y llegaba a Tui o la que se dirigía desde A Coruña a Madrid ${ }^{83}$. En consecuencia, casi medio siglo después, se continuaban señalando dos únicas rutas de calidad, los proyectos

\footnotetext{
${ }^{79}$ Memoria sobre la necesidad... págs.6-7.

${ }^{80}$ J. L. LaBrada, Descripción ..., pág. 119.

${ }^{81}$ En 1849, la Junta de Comercio de la Coruña apoyada por la Diputación Provincial solicitó la construcción de la carretera A Coruña-Ourense pasando por Melide cuando los proyectos iniciales contemplaban Santiago como nudo de comunicaciones significativo. La anónima Memoria sobre la necesidad..., publicada en 1850, defendía la necesidad de construir las vías Santiago-Lugo y Santiago-Ourense, señalando en el último caso la "economía, fomento, seguridad, protección común" que generaría dicho trazado frente al propuesto sobre Melide.

${ }^{82}$ F. de P. Mellado, Recuerdos..., págs. 3-4.

${ }^{83}$ En 1850, se había logrado reducir la duración del viaje entre A Coruña y Madrid a cinco días y medio a un promedio de 111 kilómetros diarios cuando a mediados del Siglo de las Luces el carruaje tardaba en recorrer el trayecto alrededor de 16 días, a una velocidad media de 38 kilómetros por día, la más baja de todos las rutas peninsulares. La ganancia de tiempo se debió en parte a las mejoras en las carreteras pero, sobre todo, a la mayor velocidad de los coches, gracias a los avances técnicos, véase S. MADRAZO, El sistema...,pág. 541.
} 
iniciados a finales del Setecientos, lo que da una idea del lento progreso de las infraestructuras gallegas durante la primera mitad decimonónica ${ }^{84}$. Los viajeros extranjeros que hemos mencionado en el apartado anterior resultaron testigos de ello. Además, la primera memoria (que data de 1856) sobre el estado de las carreteras españolas nos informaba de que los restantes proyectos de carreteras aprobados en las décadas anteriores estaban en proceso de construcción y alertaba de la deficiente situación de las comunicaciones gallegas:

Una de las provincias donde hay más urgente necesidad de comunicaciones interiores de caminos es Galicia, para facilitar los medios de un trabajo productivo y útil a su inmensa población, poniendo en acción todos los elementos que la naturaleza ofrece en aquella vasta provincia. La comunicación de Benavente a Vigo, con ramales a Santiago, Pontevedra y otros pueblos, importa se realice cuanto antes; estas, unidas a las que ya tiene, darán mucho impulso: sin embargo, deben trazarse muchos otros ramales desde lo interior a estos caminos principales, para establecer la circulación de los grandes espacios interiores. Cuáles sean los más importantes de estos, no es fácil decidir ahora a la Comisión por falta de indispensables datos ${ }^{85}$.

De esta manera, en vísperas de la promulgación de la trascendental Ley de Ferrocarriles de 1855, la mayoría de sus rutas interiores se referían a caminos de herradura y a escasos caminos de ruedas, aptos para algunos carruajes. A pesar del atraso comparativo en cuanto a vías de comunicación, la comunidad gallega aportó cantidades significativas a la construcción de carreteras. La memoria de 1850 calcula que, desde 1761, Galicia aportó más de 120 millones de reales con los que se construyeron 36 leguas de carreteras provinciales y una parte se distrajo hacia otros objetivos ${ }^{86}$. Asimismo, en 1842 se levantaron dos empréstitos de 9 y 8 millones de acciones con el $6 \%$ de interés, $1 \%$ de premio y $4 \%$ de amortización, para continuar las obras de las carreteras de A Coruña y de las Cabrillas. En paralelo, las provincias comenzaron a impulsar las carreteras en sus territorios ${ }^{87}$.

\footnotetext{
${ }^{84}$ F. de P. Mellado, Recuerdos de un viaje por Galicia en 1850, Madrid, Est. Tipográfico de Mellado, 1850, págs. 3-4.

${ }^{85}$ Memoria sobre el Estado de las Obras Públicas en España en 1856, presentada al Excmo. Sr. Ministro de Fomento por la Dirección General de Obras Públicas, Madrid, Imprenta Nacional, 1856.

${ }^{86}$ Memoria sobre la necesidad de...., pág. 14.

${ }^{87}$ Memoria sobre el Estado..., págs. 27-29.
} 
Cuadro 2. Estado de las carreteras gallegas a finales de 1855

\begin{tabular}{|c|c|c|}
\hline Carreteras generales & $\mathrm{Km}$ & Notas \\
\hline Madrid-A Coruña & 549,51 & Terminada \\
\hline Ferrol-Rábade & 84,68 & 13,93 km construidos y 30,64 en construcción \\
\hline Ourense-Pontevedra & 91,37 & 27,86 construidos y 63,51 km en construcción \\
\hline Madrid-Vigo & 591,72 & $\begin{array}{l}\text { 173,83 construidos (unos } 95 \text { correspondientes a tramos en } \\
\text { las provincias de Ourense y Pontevedra) y 213,95 en ejecución }\end{array}$ \\
\hline Carreteras transversales & $\mathrm{Km}$ & Notas \\
\hline Santiago-Lugo & 90,26 & 44,57 construidos y 45,69km en construcción \\
\hline Betanzos-Ferrol & 39 & 16,72 construidos y 22,28 en construcción \\
\hline Santiago-Ourense & 101,41 & 45,69 construidos y 55,72 en construcción \\
\hline Roupar-Viveiro & 42,90 & 15,04 en ejecución \\
\hline Lugo-Quiroga & 81,90 & 27,86 construidos y 5,57 en construcción \\
\hline A Coruña-Vigo & 151,56 & Terminada \\
\hline Carreteras provinciales & $\mathrm{Km}$ & Notas \\
\hline A Coruña-Bergantiños & n.d. & n.d. \\
\hline Ribadeo-Porto & n.d. & n.d. \\
\hline Vigo-Pontecesures & n.d. & n.d. \\
\hline Tui-Porriño & n.d. & n.d. \\
\hline
\end{tabular}

Fuente: Memoria sobre el Estado de las Obras Públicas en España en 1856, presentada al Excmo. Sr. Ministro de Fomento por la Dirección General de Obras Públicas, Madrid, Imprenta Nacional, 1856.

En la segunda mitad del siglo XIX, las transformaciones de la red viaria gallega se completaron con las carreteras provinciales y locales ${ }^{88}$. El ritmo de construcción de los caminos se intensificó mediada la centuria (cuadros 2 a 4). La Ley de Carreteras de 1857 introdujo dos novedades importantes ${ }^{89}$. De un lado, estableció una nueva clasificación de las vías en carreteras de primer, segundo y tercer orden. De otro, consideró por primera vez la importancia de los enlaces

\footnotetext{
${ }^{88}$ C. NARDiz, El territorio..., pág. 273.

${ }^{89}$ Gaceta de Madrid de 29 de julio de 1857, núm. 1667.
} 
entre las líneas ferroviarias y las carreteras principales. Las carreteras de primer orden se dirigían desde Madrid a las capitales de provincia, departamentos de Marina y puntos donde estaban establecidas las Aduanas marítimas, habilitadas para el comercio de importación y exportación. Quedaron también incluidos en este grupo los ramales que partían de las carreteras de primer orden o de una línea de ferrocarril hacia los puntos mencionados anteriormente o los que enlazaban dos o más ferrocarriles, siempre que pasasen por pueblos cuyo vecindario excediese las 15.000 almas. Dentro de las carreteras de segundo orden, estaban aquéllas que unían dos capitales de provincia o enlazaban el ferrocarril con una carretera de primer orden. Por último, el resto de vías quedaron clasificadas como carreteras de tercer orden.

Cuadro 3. Red viaria gallega 1847-1865

\begin{tabular}{|c|c|c|}
\hline Carreteras & Kilómetros & Número \\
\hline Carreteras de primer orden & 880,9 & 12 \\
\hline Carreteras de segundo orden & 500,5 & 16 \\
\hline Carreteras de tercer orden & 363,4 & 15 \\
\hline Caminos carreteros & 274,1 & 38 \\
\hline Caminos de herradura & $5.406,7$ & 153 \\
\hline Sendas & 121,1 & 17 \\
\hline Total & 7.548 & 251 \\
\hline Puentes & Kilómetros & Número \\
\hline De piedra & n.d. & 220 \\
\hline De mampostería & n.d. & 52 \\
\hline De madera & n.d. & 92 \\
\hline Pasaderas & n.d. & 22 \\
\hline$S / D$ & n.d. & 199 \\
\hline De pizarra & n.d. & 2 \\
\hline Total & n.d. & 587 \\
\hline
\end{tabular}

Fuente: Manuel García-Fuentes de la Fuente, La red viaria interior de Galicia en el siglo XIX (1840-1865), Servicio de Publicaciones de la Universidad de A Coruña, 1995, págs. 115-117. 
Hacia 1865 la red viaria gallega contaba con un total de 7.548 kilómetros de carreteras y caminos de diferente orden ${ }^{90}$. Las carreteras de primer, segundo y tercer orden suponían el 23\% de la red viaria gallega entre 1847 y 1865 , mientras que los caminos de herradura representaban todavía el 71\%. Dos décadas más tarde, hacia 1868 , la mayoría de estas carreteras ya se habían completado y construido otras nuevas. A estas alturas, ya podemos observar una red básica de carreteras generales y provinciales, aunque todavía estaba pendiente de ejecución el enlace norte con Asturias, una vía relegada por la prioridad que los gobernantes habían dado a las comunicaciones con Castilla y la corte madrileña a través de Lugo y el valle del Sil ${ }^{91}$. Como relataba Ford (1845), para llegar en coche desde A Coruña hasta Oviedo había que retroceder hasta Astorga, donde existía un camino mediocre que atajaba hasta León para subir de nuevo hasta Oviedo. Respecto a la provincia de Lugo, el desplazamiento por el camino del litoral desde Ribadeo a Viveiro constituía una aventura y tampoco podían llegar los coches ni los carromatos hasta Mondoñedo.

Con casi 1.500 kilómetros de costa y ante la precariedad de las carreteras regionales, los puertos se convirtieron en la ventana al exterior del Reino de Galicia, al facilitar las comunicaciones con el resto de la península y en algunos casos con el extranjero. El recuento de los puertos no resulta fácil. Según la descripción económica del Reino de Galicia de Lucas Labrada, se cifraban en 42 los volcados en el tráfico de cabotaje a principios del Ochocientos. El catastro de 1752 ofrecía una cantidad mayor, 79 puertos pesqueros. Mellado (1850) contabilizó más de cincuenta para el abrigo de los buques, una cifra más acorde con la presentada por Labrada. Su importancia varió a lo largo del siglo XVIII. Los puertos del sur, Vigo, Baiona y Pontevedra encabezaron el comercio litoral del reino de Galicia en la primera mitad de la centuria. Por el contrario, en la segunda, la preeminencia pasó a manos de los puertos del norte de la fachada atlántica, con A Coruña en primera posición. Recordemos que el eje fundamental de los proyectos viarios gallegos giró en torno a Vigo y A Coruña, enclaves portuarios que ejercían una amplia influencia sobre los puertos de segunda categoría de la Galicia norte y sur. Según Dubert (2002), los puertos gallegos, en el mejor de los casos, ejercían de apeaderos de las mercancías del comercio internacional atlántico y en el peor de los casos como simples centros de distribución de los beneficios generados por la pesca de bajura hacia las comarcas vecinas durante buena parte del siglo XVIII ${ }^{92}$.

\footnotetext{
${ }^{90}$ Manuel García-FuEnTES, La red viaria interior de Galicia en el siglo XIX (1840-1865), A Coruña, Universidad de A Coruña, 1995, págs. 115-117.

${ }^{91}$ C. NARDIZ, El territorio ..., págs. 270-272.

${ }^{92}$ Isidro DUBERT, "Las dinámicas demográficas de las pequeñas villas gallegas a finales del Antiguo Régimen”, Obradoiro de Historia Moderna, 11 (2002), pág. 66.
} 
Cuadro 4. Carreteras en Galicia, 1859 (kms.)

\begin{tabular}{|c|c|c|c|c|c|c|c|}
\hline Primer orden & Construida & En construcción & Paralizada & En proyecto & En estudio & Sin estudiar & Total \\
\hline Madrid-A Coruña & 602,966 & - & - & 29,290 & 1,602 & - & 633,858 \\
\hline Villacastín-Vigo & 367,680 & 119,382 & - & 3,840 & 88,962 & - & 579.864 \\
\hline Ponferrada-Ourense & - & 65,919 & - & - & 62,686 & 18,000 & 146,605 \\
\hline Cereixal-Ribadeo & - & 9,552 & - & - & 89,360 & & 98,912 \\
\hline Nadela-Valdeorras & 44,586 & 3,502 & - & - & 46,808 & 24,000 & 118,896 \\
\hline Lugo-Santiago & 66,190 & 36,526 & - & - & - & - & 102,716 \\
\hline Ponte Rábade-Ferrol & 48,625 & 40,232 & - & - & - & - & 88,857 \\
\hline Betanzos-Xubia & 33,760 & - & 1,580 & 1,150 & - & - & 36,490 \\
\hline Barbantiño-Pontevedra & 75,323 & 15,925 & - & - & - & - & 91,248 \\
\hline Vilalba-Luarca & - & - & - & - & 50,989 & 61,986 & 112,975 \\
\hline Cabreiros-Viveiro & 3,120 & 13,128 & - & 29,584 & - & - & 45,832 \\
\hline Carballiño-Santiago & 6,000 & 62,937 & - & - & - & 24,791 & 93,728 \\
\hline \multicolumn{8}{|c|}{ Reparto provincial de las carreteras de primer orden } \\
\hline Primer orden & Construida & En construcción & Paralizada & En proyecto & En estudio & Sin estudiar & Total \\
\hline A Coruña & 179,645 & 38,000 & 1,580 & 1,150 & - & - & 220,375 \\
\hline Lugo & 190,616 & 79,940 & - & 29,584 & 187,157 & 10,986 & 498,283 \\
\hline Ourense & 199,144 & 81,844 & - & - & 46,686 & 55,700 & 383,374 \\
\hline Pontevedra & 110,533 & 47,937 & - & - & - & 7,091 & 165,561 \\
\hline Galicia & 679,938 & 247,721 & 1,58 & 30,734 & 233,843 & 73,777 & 1267,593 \\
\hline España & 9018,911 & 818,408 & 384,274 & 1035,164 & 1803,372 & 1838,893 & 14899,022 \\
\hline
\end{tabular}

Fuente: Anuario Estadístico de España (1859), págs. 444-447.

Tras la entrada en vigor del Decreto de 1765, que establecía el servicio de Correos marítimos en el puerto de A Coruña, éste se vio favorecido de manera especial. Más tarde, su habilitación como puerto colonial adjudicó a Galicia un importante papel en la reexportación de mercancías hacia las colonias ame- 
ricanas $^{93}$. Precisamente, el crecimiento de la marina mercante y de los tráficos americanos impulsó el crecimiento de la población y favoreció la construcción y mejora de los caminos dirigidos al puerto herculino ${ }^{94}$. Pero la aprobación de los Decretos de libre comercio de 1778 supuso una inflexión a la baja en los ritmos del tráfico marítimo coruñés, a lo que se sumó el Decreto del Comercio de Neutrales en 1797. Más tarde, la pérdida de los Correos marítimos a favor de Ferrol en 1802 y la reactivación de la guerra con Inglaterra en 1804 supusieron un nuevo golpe para el comercio colonial coruñés ${ }^{95}$. Así, Vigo asumió de manera temporal el liderazgo portuario y comercial de Galicia, pero A Coruña recuperó su otrora posición adelantada en la jerarquía portuaria tras la guerra de la Independencia ${ }^{96}$. Al finalizar la primera guerra carlista el puerto coruñés había alcanzado una visible hegemonía, al menos en términos de valor de las transacciones comerciales efectuadas por cabotaje, con el extranjero y América ${ }^{97}$. El puerto de Vigo ocupaba la segunda posición, seguido a distancia por los puertos de Carril -principal puerto mercantil de Compostela-, Ribadeo, Marín, Vilagarcía, Viveiro, A Guarda y Ferrol ${ }^{98}$. Por tanto, la segunda mitad del siglo XVIII atestiguó cambios trascendentales en las vías terrestres y en el tráfico marítimo que se tradujeron en un incremento de los intercambios comerciales. Este crecimiento fue acompañado de una alteración de la jerarquía portuaria gallega y de un proceso de centralización a favor del puerto herculino.

Los medios de comunicación marítimos semejaban más eficientes que los terrestres incluso en la época previa a la difusión de los barcos de vapor. Con la llegada de éstos, las travesías se acortarían considerablemente. Así, los viajeros disuadidos por el mal estado de las carreteras gallegas disponían de la opción

\footnotetext{
${ }^{93}$ L. Alonso Álvarez, Comercio....., págs. 88 y ss.

${ }^{94}$ Pascual Madoz, Diccionario geográfico-estadístico-histórico de España y sus posesiones de Ultramar, 1845-1850.

${ }^{95}$ La Real Orden de 23 de septiembre de 1788 supuso la habilitación para recibir buques extranjeros que condujesen efectos navales. En 1797, se logró la habilitación para el comercio extranjero que se amplió a la libertad general por Real Orden de 27 de mayo de 1802. En 1827, el puerto ferrolano fue deshabilitado para el comercio extranjero y americano pero recuperó sus privilegios más tarde, véase J. Montero Arostegui, Historia y descripción de El Ferrol, El Ferrol, Gersan, 1858, reedición de 1972, pág. 480.

${ }^{96}$ Isidro DuBerT, "Comercio y tráfico marítimo en la Galicia del Antiguo Régimen, 1750-1820", Obradoiro de Historia Moderna, 17, (2008), págs. 211-243 y Enrique de Vedia y Goossens, Historia y descripción de la ciudad de La Coruña, A Coruña, Instituto José Cornide de Estudios Coruñeses, 1845 [1972], pág. 225 y ss.

${ }^{97}$ El tonelaje medio de los buques que arribaban a la bahía herculina era superior a la viguesa a mediados de la década de 1840, P. MADOZ, Diccionario...

${ }^{98}$ Precisamente el primer camino de hierro gallego, el Ferrocarril Compostelano, comunicó por vía férrea este puerto con Santiago de Compostela, véase Elvira Lindoso, "A la sombra del Arsenal: la oferta empresarial ferrolana en el siglo XIX”, Cuadernos de Estudios Gallegos, 119 (2006), págs. 269-302.
} 
de entrar en Galicia por vía marítima. Para Richard Ford (1845), el puerto de A Coruña servía de puerta de entrada para todos aquellos viajeros que desde Inglaterra se dirigían a España. De esta forma, en seis días se podía cubrir el trayecto Londres-Madrid, combinando la ruta marítima que en 72 horas realizaba el vapor Peninsular (salida Southhampton-llegada a A Coruña) con el correo real que unía la capital herculina con la española. En el caso de Vigo, los barcos de vapor de La Compañía Peninsular y Oriental de Navegación de Vapor británica que conducía el correo Real hasta Malta y Alejandría realizaban viajes periódicos entre Londres y Gibraltar, recalando en Vigo al menos una vez al mes y ofrecían pasajes de primera y segunda clase desde Southampton (17,1 y 11,15 libras respectivamente $)^{99}$. De esta manera, Vigo también se situaba en un incipiente mapa turístico para los viajeros de esta línea. De hecho, se acordó que los viajeros con destino a la India que quisiesen visitar la parte occidental de la Península Ibérica tuviesen la oportunidad, sin gastos extras, de viajar en cualquiera de los vapores correo semanales de la compañía que recalaban en puertos peninsulares como Vigo, Oporto, Lisboa, Cintra o Cádiz entre otros, conectando en Gibraltar con el vapor correo de la India para Malta y Alejandría. En paralelo, la travesía marítima hasta Vigo se acortó a tres días. Este ilustre viajero también señalaba la posibilidad de que se formase una nueva compañía para establecer una línea de vapores entre La Teste, cerca de Burdeos, y A Coruña, haciendo escala en los puertos de mar intermedios, tanto a la ida como a la vuelta. De esta manera, los ingleses que embarcasen en Southampton para el Havre tomarían allí el vapor hasta Burdeos y de allí a Pasajes, Bilbao, Santander, Gijón, Ribadeo, Ferrol o A Coruña, desde donde se podría dirigir por carretera y caminos a Santiago y Salamanca hasta Madrid. Evidentemente, la opinión de este curioso forastero está sesgada hacia los posibles pasajeros británicos que quisiesen conocer el interior de la península pero no resulta desdeñable pensar que esto suponía el reconocimiento de Galicia en los mapas viajeros de la época a pesar de las limitadas estancias de esos primeros turistas.

\section{Conclusiones}

La imagen de España en el extranjero comenzó a cambiar desde el siglo XVIII. La llegada de los Borbones, las ideas ilustradas y el empuje de la Revolución Industrial impulsaron el número de viajeros por territorio europeo que acudían a la península. Las vivencias de estos turistas pioneros quedaron recogidas en algunas guías de viaje, aunque con a diferencias territoriales. Andalucía, ambas Castillas y el Levante español adquirieron cierta fama en los primeros circuitos

\footnotetext{
99 R. Ford, Manual..., págs. 162-169.
} 
turísticos europeos en los que los británicos ejercían de creadores de tendencia. Otras regiones como Galicia, ubicada en el extremo septentrional, alejada de la Corte y con importantes barreras físicas, permanecieron más aisladas de estas incipientes rutas. En consecuencia, las crónicas viajeras por tierras gallegas escasean, pero las existentes reflejan ciertos puntos de interés turístico que se confirmarán en el futuro: centros urbanos como Santiago de Compostela, A Coruña o Lugo, los redescubiertos balnearios gallegos base del futuro turismo de salud, etc. En paralelo, dejan patentes algunas carencias como las que presentaba el tráfico terrestre.

Desde el punto de vista del transporte, componente esencial de la accesibilidad turística, algo comenzó a cambiar durante el siglo XVIII, en especial en su segunda mitad. Las primeras grandes transformaciones en el transporte terrestre galaico se iniciaron en el último tercio del Setecientos a pesar de que la construcción y reparación de carreteras siguió un curso intermitente, condicionado primero por la insuficiente capacidad de financiación y las dificultades técnicas y, más adelante, por los conflictos bélicos que sacudieron al país durante las primeras décadas del Ochocientos. Hasta que finalizó la primera guerra carlista, no se produjo un nuevo impulso en el trazado de carreteras. En cualquier caso, el estado de muchos caminos gallegos seguía calificándose de malo, pésimo o deficiente en las fuentes o los diarios de viaje de la época. Dado que no todos se encontraban facultados para soportar el tráfico rodado, el transporte se realizaba básicamente a lomos de mulas, donde los arrieros se habían convertido en un indispensable agente de transporte. Los avances en materia de carreteras resultaron insuficientes y las infraestructuras terrestres precisaban del necesario complemento del transporte marítimo. En este sentido, el tráfico marítimo, esencial en una comunidad con un amplio litoral a orillas del océano Atlántico, logró suavizar el aislamiento gallego. Con la mejora de las carreteras desde mediados del siglo XIX y la posterior conexión ferroviaria, Galicia logró reducir el grado de su aislamiento si bien éste no menguó hasta bien entrado el siglo XX. Conocer en qué medida afectó al tráfico de pasajeros constituye un tema que dejaremos para otra futura investigación.

\section{BIBLIOGRAFÍA}

Alonso Álvarez, Luis, "La crisis de la economía tradicional: continuidad y cambio en la Galicia del siglo XIX", en J. de Juana y J. Prada (coords.), Historia contemporánea de Galicia, Barcelona, Ariel, 2005, págs. 33-55.

Alonso Álvarez, Luis, Comercio colonial y crisis del Antiguo Régimen en Galicia (1778-1818), A Coruña, Xunta de Galicia, 1986.

Alonso Alvarez, Luis, Lindoso Tato, Elvira y Vilar Rodríguez, Margarita, O lecer das augas. Historia dos balnearios de Galicia, 1700-1936, Vigo, Galaxia, 2011. 
Alonso Álvarez, Luis, Vilar Rodríguez, Margarita, Lindoso Tato, Elvira, El agua bienhechora. El turismo termal en España, 1700-1936, Alhama de Granada, Observatorio Nacional del Termalismo, 2012.

Archivo del Reino de Galicia, Informe de los caminos de Galicia presentado por D. José Andrés Cornide, leg. 13, $\mathrm{n}^{\circ} 216$.

Arcos y Cuadra, Carlos, De las grandes ventajas económicas que produciría el desarrollo del turismo en España, Barcelona, Banca Mas Sardá, 1909 [1974] .

Artaza Montero, M. María, "La Junta del Reino y las carreteras de Galicia, 1775-1834”, Revista del Instituto "José Cornide” de Estudios Coruñeses, año XXII, 22 (1986), págs. 243-251.

Artaza Montero, M. María, "Vicente Vázquez del Viso y el acceso sur de Galicia a la Meseta, clave del desarrollo de Vigo", Castrelos III-IV (1990-1991), págs. 319-324.

Barreiro Fernández, Xosé Ramón y Villares Paz, Ramón, A Gran Historia de Galicia, A Coruña, La Voz de Galicia, 2007, vols. 11 y 12.

Barreiro, X., "O atraso económico e o sistema de transporte terrestre na Galicia do século XIX", Revista Galega de Economia, X, 1 (2001), págs. 63-82.

Black, Jeremy, The British Abroad. The Grand Tour in the Eighteenth Century, London, Allan Sutton, 2003.

Borrow, George, The Bible in Spain or The Journeys, Adventures, and Imprisonments of an Englishman, in an Attempt to circulate the Scriptures in the Peninsula, London, Paris, New York, Toronto and Melbourne, Cassell and Company, Ltd., 1842, reedición de 1908.

Bosarte, Isidoro, Viage artístico a varios pueblos de España con el juicio de las obras de las tres nobles artes que en ellos existen y épocas a qué pertenecen, Madrid, Imprenta Real, 1804, vol. I.

Bowles, Guillermo, Introducción a la Historia Natural, y a la Geografía Física de España, 2a edición corregida, Madrid, Imprenta Real, 1782.

Boyer, Marc, "El turismo en Europa, de la Edad Moderna al siglo XX", Historia Contemporánea (II) 25 (2002), págs. 13-31.

Cabrerizo, M., Itinerario descriptivo de las provincias de España y de sus islas y posesiones en el Mediterráneo; con una sucinta idea de su situación geográfica, población, historia civil y natural, agricultura, comercio, industria, hombres célebres, carácter y costumbres de sus habitantes, y otras noticias que amenizan su lectura. Traducción libre del que publicó en francés Mr. Alexandro Laborde en 1809. Acompaña un Atlas de 29 mapas, Valencia, Imprenta de Ildefonso Mompié, 1816.

Carmona, Xoán, El atraso industrial de Galicia, 1750-1900, Barcelona, Ariel, 1990.

Dillon, John Talbot, Travels through Spain, with a view to illustrate the natural history and physical geography of that kingdom, in a series of letters. Including the most interesting subjects contained in the Memoirs of Don Guillermo Bowles, and other Spanish Writers. Interspersed with historical anecdotes adorned with copper-plates and a new map of Spain with notes and observations relative to the arts and descriptive of modern improvements, Dublin, S. Price, W. and H. Whitestone, T. Walker, W. Gilbert, C. Jenkin, W. Hallhead, L. White, C. Talbot and P. Byrne, 1781.

Domínguez Castro, Luis, Viños, viñas e xentes do Ribeiro. Economía e patrimonio familiar, 1810-1952, Vigo, Xerais, 1992. 
Dopico, Fausto, Barreiro, X., "Os camiños da provincia de Santiago. Introducción ao estudo do transporte na Galicia do Antigo Réxime", Revista del Museo de Pontevedra, XXXII (1978), págs. 1-19.

Dubert, Isidro, "Comercio y tráfico marítimo en la Galicia del Antiguo Régimen, 1750-1820", Obradoiro de Historia Moderna, 17 (2008), págs. 211-243.

Dubert, Isidro (coord.), Historia de la Galicia Moderna, Santiago de Compostela, Servicio de Publicaciones de la USC, 2012.

Dubert, Isidro, "Las dinámicas demográficas de las pequeñas villas gallegas a finales del Antiguo Régimen", Obradoiro de Historia Moderna, 11 (2002), págs. 61-100.

Faraldo Jarillo, José M., Rodríguez-López, Carolina, Introducción a la historia del turismo, Madrid, Alianza, 2013.

Fleuriot, Jean-Marie-Jérôme, Voyage en Espagne. Cinquieme edition. Avec figures et Carte géographique, Paris, Chez J.J. Lucet, 1796.

Ford, Richard, Las cosas de España, Madrid, Turner, 1846, reedición de 1988.

Ford, Richard, Manual para viajeros por España y lectores en casa. Observaciones generales sobre el país y sus ciudades, costumbres de sus habitantes, su religión y sus leyendas, las bellas artes, la literatura, los deportes, la gastronomía, y diversas noticias sobre su historia, Madrid, Turner, 1845, reedición de 1982.

Friederich-Stegmann, Hiltrud, La imagen de España en los libros de los viajeros alemanes del siglo XVIII, Alicante, Universidad de Alicante, 2014.

García Mercadal, José, España vista por los extranjeros, Madrid, Biblioteca Nueva, 19171920 ?, 3 vols.

García Tato, Isidro, "Proyecto de reparación y modificación de trazado del camino real a su paso por Valdeorras, 1775-1805", en Actas de la Semana de Historia de Valdeorras, O Barco de Valdeorras, Instituto de Estudios Valdeorreses,1998, págs. 97-158.

García-Fuentes, Manuel, Galicia incomunicada por red viaria en el siglo XVIII, A Coruña, Servicio de Publicaciones de la Universidad de A Coruña, 1999.

García-Fuentes, Manuel, La red viaria interior de Galicia en el siglo XIX (1840-1865), A Coruña, Universidad de A Coruña, 1995.

Garrido, G. A., Aventureiros e curiosos. Relatos de viaxeiros estranxeiros por Galicia. Séculos $X V$ - XX, Vigo, Galaxia, 1994.

Gautier, T., Voyage en Espagne, Parid, Garnier-Flammarion, 1845, reedición de 1981.

Gelabert González, Juan Eloy, “Aspectos del sistema de transporte entre Galicia y Castilla en los siglos XVII y XVIII”, Archivos Leoneses, 63 (1978), págs. 109-126.

Gómez Mendoza, Antonio, Ferrocarriles y cambio económico en España (1855-1913). Un enfoque de nueva historia económica, Alianza, Madrid, 1982.

González Tascón, Ignacio, Historia del Transporte en España, INECO-TIFSA, 2005.

Gordon, Bertram M., "Turismo de Masas: un concepto problemático en la historia del siglo XX”, Historia Contemporánea (II), 25 (2002), págs. 125-156.

Herranz Loncán, Alfonso, Infraestructure and Economic Growth in Spain, 1845-1935, London School of Economics and Political Science, Tesis doctoral, 2002.

Jardine, Alexander, Letters from Barbary, France, Spain, Portugal, by an English officer. In two volumes, London, Printed for T. Cadell in the Strand, 1788. 
Laborde, Alexander de, Voyage pittoresque et historique de l'Espagne, París-Madrid, 4 vols, 1806-1820.

Labrada, J. Lucas, Descripción Económica del Reyno de Galicia por la Junta de Gobierno del Real Consulado de la Coruña, 1804.

Larrinaga, Carlos, "Aproximación biográfica al Ingeniero de Caminos del siglo XIX, Manuel Peironcely", Revista de Obras Públicas, 3.468 (2006), págs. 49-56.

Larrinaga, Carlos, "El turismo en la España del siglo XIX”, Historia Contemporánea (II), 25 (2002), págs.. 157-179.

Larrinaga, Carlos, "Ferrocarriles y termalismo: la configuración del espacio balneario en el País Vasco" en Novo, P. A., Pareja, A. (eds.), Ferrocarriles y sociedad urbana en el País Vasco, Universidad del País Vasco, 2015, págs. 208-242.

Larrinaga, Carlos, Vallejo, Rafael, "El turismo en el desarrollo español contemporáneo", Transportes, Servicios y Telecomunicaciones, 24 (2013), págs. 12-27.

Lindoso, Elvira, "A la sombra del Arsenal: la oferta empresarial ferrolana en el siglo XIX", Cuadernos de Estudios Gallegos, 119 (2006), págs. 269-302.

Lindoso, Elvira, Vilar, Margarita, "El milenario Camino de Santiago desde una perspectiva histórica: la apuesta turística de Galicia" en Carlos Barciela et al. (eds.), La evolución de la industria turística en España e Italia, Institut Balear d'Economia, Conselleria d'Economia i Hisenda, Govern de las Illes Balears, 2011.

Llopis, Enrique, "La crisis del Antiguo Régimen y la Revolución Liberal (1790-1840)", en Comín, F., Hernández, M. y Llopis, E. (eds.), Historia Económica de España, siglos X-XX, Barcelona, Crítica, 2002, págs. 165-202.

López Lambas, E., El Camino Real de Galicia. Aspectos jurídicos, Facultad de Derecho. Universidad Complutense, Madrid, Tesis doctoral inédita, 1995.

Madoz, Pascual, Diccionario geográfico-estadístico-histórico de España y sus posesiones de Ultramar, 1845-1850.

Madrazo, Santos, El sistema de transportes en España, 1750-1850, Madrid, Ediciones Turner, 2 vols, 1984.

Mellado, F. de P., Guía de viajero en España, Madrid, Establecimiento tipográfico, 1849.

Mellado, F. de P., Recuerdos de un viaje por Galicia en 1850, Madrid, Est. Tipográfico de Mellado, 1850.

Memoria sobre la necesidad de construir las carreteras provinciales de Santiago a Orense y de Santiago a Lugo, en el antiguo reino de Galicia, Madrid, Est. Tip. de H. Martínez, 1850.

Montero Arostegui, J., Historia y descripción de El Ferrol, El Ferrol, Gersan, 1858, reedición de 1972.

Moreno Garrido, Ana, "Historia del turismo: una investigación necesaria", en $V$ Jornadas de Investigación en Turismo. Turismo y Sostenibilidad, Sevilla, 17-18 de mayo, 2012, págs. 105-126.

Moreno Garrido, Ana, Historia del turismo en España en el siglo XX, Madrid, Síntesis, 2007.

Nardiz, C., El territorio y los caminos en Galicia. Planos históricos de la red viaria, A Coruña, Xunta de Galicia, 1992.

Pack, Sasha D., "Turismo en la Europa de la postguerra: de la diplomacia esterliniana al consumismo de masas”, Transportes, Servicios y Telecomunicaciones, 24 (2013), págs. 138-166. 
Pellejero, Carmelo, “Antecedentes históricos del turismo en España: de la Comisión Nacional al Ministerio de Información y Turismo (1900-1950" en Carmelo Pellejero Martínez (dir.), Historia de la economía del turismo en España, Madrid, Civitas, 1999, págs. 21-76.

Peyron, Jean-François, Essais sur l'Espagne. Nouveau Voyage en Espagne, fait en 1777 et 1778, Londres, 2 vols, 1782.

Ponz, Antonio, Viage de España, ó Cartas, en que se da noticia de las cosas mas apreciables, $y$ dignas de saberse que hay en ella, Madrid ,D. Joachin Ibarra-libreria de Esparza, 18 vols, 1772-1794.

Ringrose, D., Los transportes y el estancamiento economicos de España (1750-1850), Madrid, Ed. Tecnos, 1972.

Rubio Pérez, Laureano, Arrieros maragatos: poder, negocio, linaje y familia, siglos XVI-XIX, León, Fundación Hullera Vasco-Leonesa, 1995.

Rubio Pérez, Laureano, La burguesía maragata: dimensión social, comercio y capital en la corona de Castilla durante la Edad Moderna, León, Universidad Secretariado de Publicaciones, 1995.

Saavedra, Pegerto, La Galicia del Antiguo Régimen. Economía y Sociedad, A Coruña, Hércules, 1991.

Sánchez-Albornoz, Nicolás, España hace un siglo: una economía dual, Alianza, Madrid, 1977.

Sarmiento, Fr. Martín, Viaxe a Galicia (1745), Noia, Edición de J. L. Pensado, Departamento de Filología Románica, Universidad de Salamanca, ToxoSoutos, 1975.

Sobrado Correa, Hortensio, "Obstáculos estructurales al desarrollo de los intercambios comerciales en la Galicia de la Edad Moderna”, Obradoiro de Historia Moderna, 17 (2008), págs. 303-324.

Stoye, John Walter, English Travellers Abroad, 1604-1667: Their Influence in English Society and Politics, London, J. Cape, 1952.

Suárez Freyre, J. F., Viage de Galicia desde la Villa de Benavente o breve descripción de sus dos carreteras: de la construida desde Astorga a La Coruña y de la que debe construirse desde la villa de Benavente a la ciudad de Orense, Santiago y Vigo con algunas observaciones acerca de las obras, utilidad y circunstancias de cada una, Santiago, Ed. Oficina de D. Manuel Antonio Rey, 1813.

Swinburne, Henry, Travels through Spain, in the years 1775 and 1776: in which several monuments of Roman and Moorish architecture are illustrated by accurate drawings taken on the spot, London, P. Elmsly, 1779.

Townsend, J., Viaje por España en la época de Carlos III (1786-1787), Madrid, Turner, 1791, Reedición de 1988.

Twiss, Richard, Travels through Portugal and Spain, in 1772 y 1773. Printed by Richard Twiss with an Appendix, Sold by G. Robinson, T. Becket and J. Robson, London-Dublin, 2 vols., 1775.

Urgorri, F., Fembiella, L., El Antiguo Camino Real de La Coruña a Santiago: el Camino de Faro o Camino Francés de Poulo, A Coruña, Fundación Caixa Galicia, 1992.

Vallejo, Rafael, "Economía e historia del turismo español del siglo XX", Historia Contemporánea, (II), 25 (2002), págs. 203-232. 
Vallejo, Rafael, "Turismo y desarrollo económico de España durante el franquismo, 1939-1975" en Revista de la Historia de la Economía y de la Empresa, VII (2013), págs. 423-452.

Vedia y Goossens, Enrique de, Historia y descripción de la ciudad de La Coruña, A Coruña, Instituto José Cornide de Estudios Coruñeses, 1845 [1972].

Vega, Jesusa, "Viajar a España en la primera mitad del siglo XIX: Una aventura lejos de la civilización”, RDTP, LIX, 2 (2004), págs. 93-125. 
